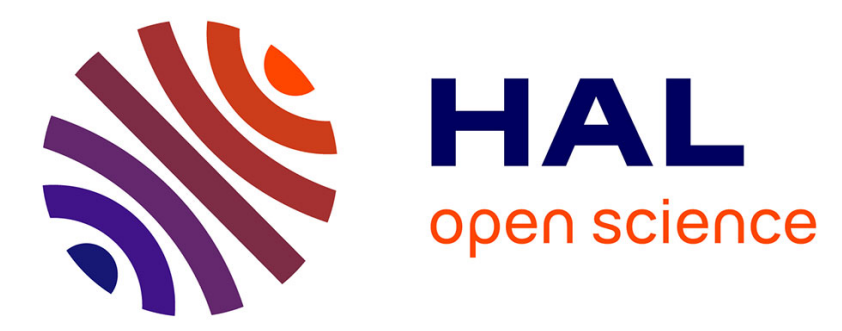

\title{
Dual Metal-Acid Pd-Br Catalyst for Selective Hydrodeoxygenation of 5-Hydroxymethylfurfural (HMF) to 2, 5-Dimethylfuran at Ambient Temperature
}

Dan Wu, Songwei Zhang, Willinton y Hernández, Walid Baaziz, Ovidiu Ersen, Maya Marinova, Andrei Khodakov, Vitaly Ordomsky

\section{To cite this version:}

Dan Wu, Songwei Zhang, Willinton y Hernández, Walid Baaziz, Ovidiu Ersen, et al.. Dual MetalAcid Pd-Br Catalyst for Selective Hydrodeoxygenation of 5-Hydroxymethylfurfural (HMF) to 2, 5Dimethylfuran at Ambient Temperature. ACS Catalysis, In press. hal-03052328

\section{HAL Id: hal-03052328 https://hal.science/hal-03052328}

Submitted on 10 Dec 2020

HAL is a multi-disciplinary open access archive for the deposit and dissemination of scientific research documents, whether they are published or not. The documents may come from teaching and research institutions in France or abroad, or from public or private research centers.
L'archive ouverte pluridisciplinaire HAL, est destinée au dépôt et à la diffusion de documents scientifiques de niveau recherche, publiés ou non, émanant des établissements d'enseignement et de recherche français ou étrangers, des laboratoires publics ou privés. 


\section{Dual Metal-Acid Pd-Br Catalyst for Selective Hydrodeoxygenation of 5-Hydroxymethylfurfural (HMF) to 2, 5-Dimethylfuran at Ambient Temperature}

Dan Wu, ${ }^{a, b}$ Songwei Zhang, ${ }^{c}$ Willinton Y. Hernández, ${ }^{a}$ Walid Baaziz, ${ }^{d}$ Ovidiu Ersen, ${ }^{d}$ Maya Marinova, ${ }^{e}$ Andrei Y. Khodakov, ${ }^{b} *$ and Vitaly V. Ordomsky ${ }^{b} *$

a Eco-Efficient Products and Processes Laboratory (E2P2L), UMI 3464 CNRS-Solvay, 201108 Shanghai, People's Republic of China,

${ }^{b}$ Univ. Lille, CNRS, Centrale Lille, ENSCL, Univ. Artois, UMR 8181 - UCCS - Unité de Catalyse et Chimie du Solide, F-59000 Lille, France, E-mail: vitaly.ordomsky@univ-lille.fr ; andrei.khodakov@univ-lille1.fr;

${ }^{c}$ School of Physical Science and Technology, Shanghai Tech University, Shanghai 201210, People's Republic of China.

${ }^{d}$ Institut de Physique et Chimie des Matériaux de Strasbourg (IPCMS)-UMR 7504 CNRS, Université de Strasbourg, 23 rue du Loess, BP 43, 67034 Strasbourg Cedex 2, France

${ }^{e}$ Univ. Lille, CNRS, INRA, Centrale Lille, ENSCL, Univ. Artois, FR 2638 - IMEC Institut Michel-Eugène Chevreul, F-59000 Lille, France 


\section{ABSTRACT.}

Supported metal catalysts have found broad applications in heterogeneous catalysis. In the conventional bifunctional catalyst, the active metal sites are associated with the metal nanoparticles, while the acid sites are usually localized over the oxide support. Herein, we report a novel type of supported metal bifunctional catalyst, which combined the advantages of the promotion and bifunctionality. The catalyst was designed by the pretreatment of supported palladium catalysts with bromobenzene compounds. The promotion with bromine creates Brønsted acid sites, which are localized directly on the surface of metal nanoparticles. An intimacy between metal and acid functions in this bifunctional catalyst generates unique catalytic properties in hydrodeoxygenation of 5-hydroxymethylfurfural to dimethylfuran, occurring with the yield up to $96 \%$ at ambient temperature under 5 bar of $\mathrm{H}_{2}$. The catalyst exhibits stable catalytic performance.

KEYWORDS. Heterogeneous catalysis; Bifunctional catalysis; Biomass; Hydrodeoxygenation; Dimethylfuran. 


\section{Introduction}

Chemical reactions over heterogeneous catalysts usually involves multiple steps which may occur over different active sites. A rational combination of different active sites in one catalytic process for chemoselective transformation is highly desired ${ }^{[1-3]}$. While noble metal catalyst is active for hydrogenation, acid catalysts are effective for isomerization, dehydration and condensation ${ }^{[4-5]}$. Bifunctional metal-acid catalysts containing both metal and acid sites have been developed and widely applied for numerous important processes including conversion of biomass-derived platform molecules ${ }^{[6-9]}$. 5-hydroxymethylfurfural (HMF), which is produced from the abundant lignocellulosic biomass, has attracted intensive attention because of its conversion to value-added chemicals such as 2,5-bis(hydroxymethyl)furan (BHMF), 2,5-bis(hydroxymethyl)tetrahydrofuran (DHMTHF) and 2,5-dimethylfuran (DMF) ${ }^{[10-14]}$. Among them, DMF has been proposed as a promising renewable transportation fuel due to its high boiling point, high energy density, high octane number and low water solubility ${ }^{[14]}$. Besides, DMF can be converted to $p$-xylene (PX) via Diels-Alder reactions, which is an important raw material in the production of polyethylene terephthalate $(\mathrm{PET})^{[15-17]}$.

There are two groups of catalysts which have been proposed for conversion of HMF to DMF: 1) Pd, Pt, $\mathrm{Ru}, \mathrm{Ir}, \mathrm{Co}, \mathrm{Ni}$ and $\mathrm{Cu}$-based monometallic or bimetallic catalysts, which perform hydrogenolysis of $\mathrm{C}-\mathrm{O}$ bond at the temperatures in the range of 150 250 ${ }^{\circ} \mathrm{C} . \quad\left[\begin{array}{ll}14, & 18-23\end{array}\right]$ and 2) bifunctional metal-acid catalysts for 
hydrodeoxygenation through protonation of the hydroxyl groups and dehydration at milder reaction conditions $\left(60 \sim 130{ }^{\circ} \mathrm{C}\right){ }^{[24-33]}$. The disadvantage of the first route is that the high reaction temperature induces polymerization of highly reactive HMF to humins ${ }^{[34]}$. The best performance has been achieved so far over metal-based catalysts in the presence of homogeneous acids, however, this strategy induces environmental problems related to separation, recycling of acid solutions and corrosion of equipment [25]

Traditional heterogeneous bifunctional metal catalysts with acidic supports have been reported for the production of DMF from HMF at mild conditions ${ }^{[28-33]}$. Zu et al. have developed a heterogeneous $\mathrm{Ru} / \mathrm{Co}_{3} \mathrm{O}_{4}$ catalyst for hydrodeoxygenation of $\mathrm{HMF}$ to $\mathrm{DMF}$ and unveiled that $\mathrm{Ru}$ was responsible for hydrogenation of carbonyl groups to the hydroxyl groups, while $\mathrm{CoO}_{\mathrm{x}}$ species played an important role in the hydrogenolysis of hydroxyl groups to methyl groups ${ }^{[28]}$. A $93.4 \%$ yield was achieved at the temperature of $130{ }^{\circ} \mathrm{C}$. Bifunctional $\mathrm{Pd}-\mathrm{Cs}_{2.5} \mathrm{H}_{0.5} \mathrm{PW}_{12} \mathrm{O}_{40} / \mathrm{K} 10$ clay has been found as an efficient catalyst for HMF deoxygenation ${ }^{[29]}$. With the rapid hydrogenolysis rate facilitated by the acidic support, a yield up to $80 \%$ could be obtained at $90{ }^{\circ} \mathrm{C}$. Note that in the conventional catalysts, metal and acid functions are spatially separated. Metal sites are localized over metal nanoparticles, while acid sites are related to the zeolite phase. It has been shown that the relative proximity of metal sites in the $\mathrm{Pt} / \mathrm{Al}_{2} \mathrm{O}_{3}$ catalysts modified by phosphonic acid could significantly improve the selectivity and activity towards hydrodeoxygenation (HDO) of alcohols [35]. Traditional bifunctional metal-acid catalysts such as metals supported over 
zeolites, cannot therefore provide a high level of intimacy between metal and acid sites for deoxygenation and result in undesirable hydrogenation and polymerization reactions ${ }^{[30-32]}$.

Combining metal and acid properties in a close proximity over the surface of metal nanoparticles could provide a breakthrough in the development of highly efficient processes for deoxygenation reactions ${ }^{[36]}$. These sites would allow at the same time hydrogenation or carbonyl group, protonation, dehydration and hydride addition as the final step (Scheme 1). There are very few papers about modification of nanoparticles of noble metals with halogens. Precious metal catalysts covered by bromide salts have been reported for the selective production of cyclohexanone from aromatic ethers ${ }^{[37]}$. The Au-Pd catalysts on $\mathrm{MgO}$ and $\mathrm{C}$ supports for the direct synthesis of hydrogen peroxide were pretreated with aqueous bromide solution ${ }^{[38]}$. The bromide pretreatment significantly enhanced $\mathrm{H}_{2} \mathrm{O}_{2}$ productivity over the MgO-based catalysts. The promotional effect has been correlated to selective poisoning of sites responsible for $\mathrm{H}_{2} \mathrm{O}_{2}$ hydrogenation and decomposition. Our approach here relies on the deposition of electronegative $\mathrm{Br}$ atoms over $\mathrm{Pd}$ surface by bromobenzene hydrogenolysis, which induces the generation of strong Brønsted acidity by hydrogen dissociation over Pd. These dual sites enable extremely selective hydrodeoxygenation of $\mathrm{HMF}$ to $\mathrm{DMF}$ at ambient temperature which has been achieved so far. 


\section{Experiment section}

\subsection{Materials}

$\mathrm{Pd} / \mathrm{Al}_{2} \mathrm{O}_{3}$ and $\mathrm{Pd} / \mathrm{C}$ (5 wt. \% metal loading) were purchased from Johnson Matthey Chemicals Company. $\mathrm{Pd} / \mathrm{SiO}_{2}(5$ wt.\%) was a home-made catalyst prepared by incipient wetness impregnation. Pd black, bromobenzene, iodobenzene, chlorobenzene, and ammonium bromide $\left(\mathrm{NH}_{4} \mathrm{Br}\right)$ were purchased from Alfa-Aesar Materials Company. Tetrahydrofuran (THF), 5-hydroxymethylfurfural (HMF), 1-bromohexadecane, pyridine, elemental $\mathrm{Br}_{2}, \mathrm{HBr}, \mathrm{Pd}^{0}\left(\mathrm{PPh}_{3}\right)_{4}$, benzyl alcohol, dimethylfuran (DMF), 3-phenylropanal, and biphenyl have been supplied by Sigma-Aldrich Company. All chemicals were of analytical grade and used as received without further purification.

\subsection{Catalytic reactions}

The hydrogenation reaction has been performed in a $25 \mathrm{ml}$ stainless-steel autoclave equipped with a magnetic stirrer, pressure gauge and an automatic temperature controller. Typically, for the hydrodeoxygenation of HMF, $5 \mathrm{~g}$ of THF, $0.1 \mathrm{~g}$ of $\mathrm{HMF}$ and $50 \mathrm{mg}$ of catalyst with or without $10 \mu \mathrm{l}$ of bromobenzene were added into the reactor. Afterward, the reactor was sealed and pressurized by 5 or 20 bar of hydrogen, followed by heating up to the target temperature with continuous magnetic stirring. After the reaction, the reactor was cooled down, the solution was separated by filtration and the products were identified by GC-MS (Agilent Technologies 5977A MSD with Agilent Technologies 7890B GC system equipped 
with HP-5 capillary column) and quantified by GC (Agilent Technologies 7820A, equipped with HP-5 capillary column and flame ionization detector) with biphenyl as the internal standard.

The conversion of HMF, selectivity and yield to corresponding products were defined as follows:

$$
\begin{gathered}
\text { Conversion }(\%)=1-\frac{n_{A}}{n_{A}^{o}} \\
\text { Selectivity to the product } \mathrm{p}(\%)=\frac{n_{p}}{n_{A}^{o}-n_{A}} \\
\text { Yield }(\%)=\text { Conversion } \times \text { Selectivity }
\end{gathered}
$$

$n_{A}$ and $n_{A}^{o}$ refers to the final, initial number of the moles of HMF, respectively. $n_{p}$ is number of the moles of converted HMF to product $\mathrm{p}$. Biphenyl was used as an internal standard for quantification.

Kinetic reaction rate constants $(\mathrm{k})$ of benzyl alcohol hydrodeoxygenation to toluene were calculated by linearization of the reaction rate by the first-order reaction law as follows:

$$
\ln (\mathrm{A})=-\mathrm{kt}+\ln \mathrm{A}_{0},
$$

where $\mathrm{A}$ is the concentration of benzyl alcohol $(\mathrm{mol} / \mathrm{L}), \mathrm{k}$ is rate constant $\left(\mathrm{min}^{-1}\right)$, $\mathrm{t}$ is time (min). $\mathrm{A}_{0}$ is the initial concentration of benzyl alcohol. A plot of $\ln (\mathrm{A}) \mathrm{vs}$ time gives the rate constant from the slope of the linear regression equation.

Activation energy $\mathrm{E}_{\mathrm{a}}$ was calculated as follows:

$$
E_{a}=R T_{1} T_{2} \times \frac{\ln k_{2}-\ln k_{1}}{T_{2}-T_{1}}
$$

where $\mathrm{k}_{1}$ and $\mathrm{k}_{2}$ represent the kinetic reaction rate constants measured at the $T_{1}$ and $\mathrm{T}_{2}$ temperatures, respectively. 


\subsection{Catalyst preparation}

To prepare the BrBen pre-treated $\mathrm{Pd}$ catalysts, typically, $200 \mathrm{mg}$ of $\mathrm{Pd} / \mathrm{Al}_{2} \mathrm{O}_{3}$, $\mathrm{Pd} / \mathrm{C}, \mathrm{Pd} / \mathrm{SiO}_{2}$, or Pd black catalyst, together with $50 \mu \mathrm{l} \mathrm{BrBen}$ and $5 \mathrm{~g}$ THF were added in the autoclave reactor. Afterwards, the reactor was sealed and pressurized by 20 bar of hydrogen, followed by heating up to $60{ }^{\circ} \mathrm{C}$ with continuous magnetic stirring for $1 \mathrm{~h}$. Finally, the catalyst and liquid phase were separated by centrifugation and washed with THF for 3 times and dried at $60{ }^{\circ} \mathrm{C}$ overnight.

$\mathrm{Br}_{2}-\mathrm{Pd} / \mathrm{Al}_{2} \mathrm{O}_{3}$ and $\mathrm{HBr}-\mathrm{Pd} / \mathrm{Al}_{2} \mathrm{O}_{3}$ catalysts were prepared by modification of $\mathrm{Pd} / \mathrm{Al}_{2} \mathrm{O}_{3}$ under ambient conditions. Typically, $200 \mathrm{mg} \mathrm{Pd} / \mathrm{Al}_{2} \mathrm{O}_{3}$ catalyst, an equivalent amount of $\mathrm{Br}_{2}$ or $\mathrm{HBr}(0.3 \mathrm{mmol}$ of $\mathrm{Br})$, and $5 \mathrm{~g}$ THF were stirred together under ambitious conditions for $15 \mathrm{~min}$. Afterwards, the catalysts were separated by centrifugation and washed with THF for 3 times. Finally, the catalysts were dried at $60^{\circ} \mathrm{C}$ overnight.

\subsection{Catalyst characterization}

For transmission electron microscopy (TEM) analysis, the scanning mode were carried out on a JEOL 2100 FEG S/TEM microscope operated at $200 \mathrm{kV}$ and equipped with a spherical aberration probe corrector. Before analysis, the samples were dispersed in ethanol and deposited on a holey carbon coated TEM grid. In STEM, the images were recorded using a high-angular annular dark field (HAADF) detector with inner and outer diameters of about 73 and 194 mrad. Energy Dispersive X-ray Spectroscopy (EDS) analyses allowing for the elemental mapping of $\mathrm{Pd}$ and $\mathrm{Br}$, 
were performed in STEM using a JEOL Silicon Drift Detector (DrySD60GV, sensor size $60 \mathrm{~mm}^{2}$ ) with a solid angle of approximately $0.6 \mathrm{srad}$.

X-ray fluorescence (XRF) analysis was performed with the use of an energy dispersive micro-X Ray Fluorescence spectrometer M4 TORNADO (Bruker). This instrument is equipped with 2 anodes a Rhodium X-ray tube $50 \mathrm{kV} / 600 \mathrm{~mA}(30 \mathrm{~W})$ and a Tungsten X-Ray tube $50 \mathrm{kV} / 700 \mathrm{~mA}(35 \mathrm{~W})$. For sample characterization, the X-rays Rhodium with a polycapillary lens enabling excitation of an area of $200 \mu \mathrm{m}$ was used. The detector used was a Silicon-Drift-Detector $\mathrm{Si}(\mathrm{Li})$ with $<145 \mathrm{eV}$ resolution at $100000 \mathrm{cps}(\mathrm{Mn} \mathrm{K \alpha})$ and cooled with a Peltier cooling $\left(253^{\circ} \mathrm{K}\right)$. The measurement was done under vacuum (20 mbar). The elements, that can be measured by this instrument unit range from sodium (Na) to uranium (U). Quantitative analysis was done using fundamental parameter (FP) (standardless). As elements are present in stoichiometric compounds, its formula was used for quantification of the weight percent of each element.

X-ray photoelectron spectroscopy (XPS) analysis has been performed in a ThermoFischer ESCALAB 250Xi photoelectron spectrometer using monochromated X-ray irradiation $\mathrm{Al} \mathrm{K} \alpha(1486.7 \mathrm{eV})$ and $180^{\circ}$ double-focusing hemispherical analyzer with a six-channel detector. The binding energy $(\mathrm{BE})$ of the photoemission spectra was calibrated to $\mathrm{Al} 2 \mathrm{p}$ peak with $\mathrm{BE} 74.5 \mathrm{eV}$ for Al-containing samples and to adventitious carbon C 1s peak with BE $284.8 \mathrm{eV}$ for others.

The CO pulse adsorption was performed on AutoChem II 2920 apparatus from Micromeritics. $80 \mathrm{mg}$ of sample was loaded in a quartz reactor and then the samples 
were firstly reduced in a flow of $5 \% \mathrm{H}_{2} / \mathrm{Ar}$ flow $(60 \mathrm{ml} / \mathrm{min})$ with heating rate 10 ${ }^{\circ} \mathrm{C} / \mathrm{min}$ at $60{ }^{\circ} \mathrm{C}$ for $0.5 \mathrm{~h}$ then cooling down to $45^{\circ} \mathrm{C}$. The catalyst has been treated by CO pulses in a He flow till full saturation.

Fourier transform infrared (FTIR) spectra were recorded using a Thermo Fisher Scientific Nicolet 6700 FTIR (32 scans at a resolution of $4 \mathrm{~cm}^{-1}$ ) equipped with a mercury cadmium telluride (MCT) detector. Pyridine and CO-FTIR experiments were performed in a vacuum cell (less than $10^{-5}$ torr). The catalyst samples for analysis were pressed in a $40 \sim 50 \mathrm{mg} / \mathrm{cm}^{2}(\mathrm{D}=13 \mathrm{~mm})$ self-supporting discs. Before the analysis, all the samples were reduced at $60{ }^{\circ} \mathrm{C}$ for $1 \mathrm{~h}$ with subsequent vacuum treatment for $3 \mathrm{~h}$. $\mathrm{CO}$ adsorption has been performed by the addition of $\mathrm{CO}$ doses in the cell at room temperature till full saturation. Pyridine (Py) adsorption has been performed in the same way by the addition of Py doses. For some experiments, 500 torr of hydrogen have been introduced in the cell after Py adsorption.

\section{Results and discussions}

\subsection{HMF deoxygenation over the Pd-Br catalyst at $60^{\circ} \mathrm{C}$}

Hydrogenation of HMF has been conducted at $60{ }^{\circ} \mathrm{C}$ under 20 bar of $\mathrm{H}_{2}$ pressure for $1 \mathrm{~h}$ both over promoted and unpromoted Pd catalysts. First of all, hydrogenation of $\mathrm{HMF}$ was performed over the non-promoted $5 \mathrm{wt} \% \mathrm{Pd} / \mathrm{Al}_{2} \mathrm{O}_{3}$ catalyst. In agreement with previous reports, the main products were BHMTHF and 1,2,6-hexanetriol (HT), respectively, representing the strong hydrogenation and hydrogenolysis abilities of $\mathrm{Pd}$

(Table 1, Entry 1) ${ }^{[39]}$. The main reaction products are given in Table $\mathbf{1}$ and the 
detailed other product description is shown in Table S1, SI. Surprisingly, when $10 \mu 1$ of BrBen was added, the product distribution has changed to mainly DMF with $96.7 \%$ yield (Table 1, Entry 2). The promotion effect of BrBen could be observed as well for other Pd catalysts supported over $\mathrm{SiO}_{2}\left(\mathrm{Pd} / \mathrm{SiO}_{2}\right)$ and $\mathrm{C}(\mathrm{Pd} / \mathrm{C})($ Table 1, Entry 5-10). The non-supported Pd without promoter also provides BHMTHF as the main product (selectivity of $81.3 \%$ ), while DMF was the dominant product in the presence of BrBen (selectivity of $82.1 \%$ ). It is worth noting that without $\mathrm{Pd}, \mathrm{BrBen}$ cannot catalyze the transformation of HMF (Table 1, Entry 11). These results confirm that BrBen totally changes the selectivity patterns during HMF hydrogenation over both supported and non-supported Pd catalysts. The effect seems to be not related to the catalytic support.

To clarify the effect of $\mathrm{Br}$ on the catalytic system, we have performed the pre-treatment of Pd catalysts by BrBen and hydrogen without HMF in the reactor. After the pretreatment, the $\mathrm{Br}-\mathrm{Pd} / \mathrm{Al}_{2} \mathrm{O}_{3}, \mathrm{Br}-\mathrm{Pd} / \mathrm{C}, \mathrm{Br}-\mathrm{Pd} / \mathrm{SiO}_{2}$ catalysts and $\mathrm{Br}-\mathrm{Pd}$ black have been separated from the liquid phase, thoroughly washed and tested in the conversion of HMF (Table 1, Entry 12-15). Interestingly, although the pre-treated catalyst showed a lower activity at the same reaction conditions in comparison to the non-modified catalyst in the presence of BrBen, the selectivity has totally changed. The main products of the reaction over the non-promoted Pd catalysts were BHMTHF and HT. Over the pre-modified Pd-Br catalysts, the product distribution has changed to BHMF, MFA and DMF. It is worth noting that BHMF and MFA can be considered as intermediates for hydrodeoxygenation of HMF to DMF ${ }^{[40]}$. They exhibit high 
selectivity over $\mathrm{Pd} / \mathrm{Al}_{2} \mathrm{O}_{3}$ at lower conversion in the presence of BrBen (Table 1, Entry 3-4). To investigate the mechanism of promotion of $\mathrm{Pd} / \mathrm{Al}_{2} \mathrm{O}_{3}$ using $\mathrm{BrBen}$, the reaction mixture after catalysis has been analyzed by GC-MS. The presence of benzene in the reaction mixture indicates the dehalogenation of BrBen over the $\mathrm{Pd}$ surface (Figure S1, SI). Therefore, it is rationally to suspect that the hydrogenolysis of BrBen over Pd surface leads to the modification of Pd surface with $\mathrm{Br}$ atoms and the newly formed $\mathrm{Pd}-\mathrm{Br}$ sites could be responsible for the changes of selectivity during the conversion of HMF.

The heterogeneous nature of the $\mathrm{Pd}-\mathrm{Br}$ catalyst was further confirmed by a hot filtration test (Figure S2, SI). The catalyst has been filtered out and the test has been continued without additional activity. It indicates that the reaction was catalyzed by heterogeneous $\mathrm{Pd}-\mathrm{Br}$ sites. This conclusion has been further supported by HMF conversion over homogeneous $\mathrm{Pd}^{0}\left(\mathrm{PPh}_{3}\right)_{4}$ catalyst in the presence and without BrBen. As shown in Table S2, SI, both catalytic systems show almost no activity for HMF conversion.

\subsection{HMF deoxygenation at ambient temperature}

HMF is a complex biomass-based molecule, which is not stable during thermochemical reactions due to fast condensation reactions ${ }^{[41-42]}$. Thus, it would be highly desirable to perform hydrodeoxygenation at ambient reaction conditions where condensation does not take place. Hydrogenation of HMF at mild reaction conditions over $\mathrm{Br}-\mathrm{Pd} / \mathrm{Al}_{2} \mathrm{O}_{3}$ catalyst has been performed at $30{ }^{\circ} \mathrm{C}$ and 5 bar of $\mathrm{H}_{2}$ for $6 \mathrm{~h}$ (Table 1, Entry 16-18). These are rather mild conditions in comparison with the $1 \mathrm{~h}$ tests 
performed at $60{ }^{\circ} \mathrm{C}$ and 20 bar of $\mathrm{H}_{2}$. Even at such mild conditions, HMF could be converted to DMF with yield of $95.3 \%$ over the $\mathrm{Br}-\mathrm{Pd} / \mathrm{Al}_{2} \mathrm{O}_{3}$ catalyst prepared by pre-treatment of the parent $\mathrm{Pd} / \mathrm{Al}_{2} \mathrm{O}_{3}$ with BrBen. A similar performance has been observed in the presence of BrBen added to the reactor. These results demonstrate that the hydrodeoxygenation of HMF could be carried out over Pd-Br catalyst with high selectivity and conversion at ambient temperature. To the best of our knowledge, this is the first ever reported heterogeneous catalyst for hydrodeoxygenation of HMF with $\mathrm{H}_{2}$ at ambient temperature.

\subsection{Other promoting agents}

Other bromine sources such as 1-bromohexadecane, ammonium bromide, elemental $\mathrm{Br}_{2}$, and $\mathrm{HBr}$ have been tested for this reaction (Table 1, Entry 19-22). With addition of 1-bromohexadecane and ammonium bromide, the resulting catalysts, however, demonstrated the catalytic performance similar to the non-promoted $\mathrm{Pd}$ catalyst. This fact is due to the insignificant hydrogenolysis of these bromine compounds over the Pd surface. The absence of the products of decomposition of 1-bromohexadecane during these pretreatments was further confirmed by the GC-MS analysis (Figure S3, SI). Oxidative dissociation of elemental $\mathrm{Br}_{2}$ on the $\mathrm{Pd}$ surface has been reported ${ }^{[43]}$, however, in the presence of $\mathrm{H}_{2}$, elemental $\mathrm{Br}_{2}$ cannot efficiently modify the Pd surface and demonstrates the product distribution similar to the initial Pd catalyst. It is interesting to note that the addition of $\mathrm{HBr}$ leads to the synthesis of $\mathrm{DMF}$ as the main product. However, in comparison to the promotion effect of BrBen, $\mathrm{HBr}$ leads to lower conversion (81\%) and a significant amount of side-products. 
These results are in agreement with the literature which showed that side-reactions such as acid-catalyzed condensation could happen in the presence of homogeneous acids ${ }^{[24]}$. The decrease of activity could be explained by the competitive adsorption of $\mathrm{HBr}$ over Pd surface.

Moreover, elemental $\mathrm{Br}_{2}$ and $\mathrm{HBr}$ were used as bromine source to pre-treat the initial $\mathrm{Pd} / \mathrm{Al}_{2} \mathrm{O}_{3}$ catalyst. It is interesting to note that $\mathrm{Br}_{2}-\mathrm{Pd} / \mathrm{Al}_{2} \mathrm{O}_{3}$ produces $\mathrm{DMF}$ as the main product (Table S2, SI), indicating the modification of $\mathrm{Pd}$ surface with $\mathrm{Br}$ at ambient conditions in comparison with no effect of $\mathrm{Br}_{2}$ added during reaction. However, $\mathrm{HBr}-\mathrm{Pd} / \mathrm{Al}_{2} \mathrm{O}_{3}$ catalyst produces DMTHF as the main product (selectivity is $61.9 \%$ ), which can be explained by the modification of $\mathrm{Al}_{2} \mathrm{O}_{3}$ with $\mathrm{HBr}$ pre-treatment. The high reactivity of elemental $\mathrm{Br}_{2}$ and $\mathrm{HBr}$ can result in the reaction of bromine source with support with the generation of non-selective sites and partial dissolution of support. Pre-treatment by BrBen provides a selective tool for modification of only Pd surface in the presence of $\mathrm{H}_{2}$. As illustrated in Figure 1, the oxidative addition of BrBen to the surface $\mathrm{Pd}$ atoms leads to the formation of (Br)-Pd-Ben, which further reacts with $\mathrm{H}_{2}$ to form $\mathrm{Pd}(\mathrm{H})(\mathrm{Br})$ and release of benzene (Figure S4, SI). At the same time, pure $\mathrm{Al}_{2} \mathrm{O}_{3}$ support cannot perform the hydrogenolysis of $\mathrm{BrBen}$ at the same reaction conditions.

The effect of other halogens such as $\mathrm{Cl}$ and I has been also studied. The HMF conversion over $\mathrm{Pd} / \mathrm{Al}_{2} \mathrm{O}_{3}$ was investigated in the presence of ClBen and IBen (Table 1, Entry 23-24). The presence of iodine resulted in the complete deactivation of the catalyst. Our earlier studies have confirmed that the treatment of Pd by organic iodine 
leads to full coverage of Pd surface by $\mathrm{I}^{[36]}$. The addition of ClBen leads to low deoxygenation activity and noticeable hydrogenation of furan-rings. Thus, in the row of halogens, the activity of the catalysts in HMF hydrogenation increases in row $\mathrm{I}<\mathrm{Br}<\mathrm{Cl}$ with zero activity of the iodine-promoted catalysts, because of full coverage of Pd by iodine and low effect of chlorine on the Pd catalyst. The increase in the electronegativity of the elements in this row should also lead to an increase in the polarity of the Pd-Hal bond. Bromine demonstrates intermediate activity with significant enhancement of selectivity toward deoxygenation instead of the aromatic ring hydrogenation. Moreover, the stability of $\mathrm{Cl}$ on the $\mathrm{Pd}$ surface was verified by reusing the $\mathrm{Cl}-\mathrm{Pd} / \mathrm{Al}_{2} \mathrm{O}_{3}$ catalyst consequently for three cycles. As indicated in Figure S5, SI, the deoxygenation ability of Cl-Pd catalyst significantly decreased in the second cycle and the selectivity in the third cycle was similar to the initial $\mathrm{Pd} / \mathrm{Al}_{2} \mathrm{O}_{3}$. These results suggest the low stability of $\mathrm{Cl}$ on $\mathrm{Pd}$ surface in the reaction.

To provide more insights into the reaction pathway, the kinetic study of HMF hydrogenation over $\mathrm{Br}-\mathrm{Pd} / \mathrm{Al}_{2} \mathrm{O}_{3}$ has been performed at ambient temperature (Figure 1). As expected, the conversion of HMF increases with the increase in the reaction time. The selectivity to BHMF is close to $100 \%$ at the initial reaction time. This suggests that $\mathrm{BHMF}$ is the primary product of the reaction over $\mathrm{Br}-\mathrm{Pd} / \mathrm{Al}_{2} \mathrm{O}_{3}$ due to the fast hydrogenation of the carbonyl group in the HMF molecule. Afterward, this product has been transformed into MFA and DMF which seem to be secondary products MFA is produced by deoxygenation of one of the hydroxyl groups of BHMF, while DMF is produced by simultaneous deoxygenation of both BHMF hydroxyl 
groups. Finally, MFA decreases at higher reaction time due to transformation to DMF. It is worth to note that when the reaction time progresses, the rapid decrease of BHMF and the slow increase of MFA and DMF confirmed the high deoxygenation ability of $\mathrm{Pd}-\mathrm{Br}$ catalyst, which can effectively deoxygenate hydroxyl groups. Thus, as indicated in Table 1, the conversion of HMF molecules proceeds with intermediate hydrogenation of the carbonyl group and subsequent hydrodeoxygenation of hydroxyl groups to methyl groups. For comparison, the reaction kinetics at the same reaction conditions has been measured for $\mathrm{Pd} / \mathrm{Al}_{2} \mathrm{O}_{3}$ (Figure S6, SI). The $\mathrm{Pd}-\mathrm{Br}$ catalyst yields a high amount of BHMF at initial reaction time, however, $\mathrm{Pd}$ without modification yields mainly BHMTHF for the whole reaction time (Figure S6, SI). The TOF numbers of the primary products are given in Table S3, SI. The Pd-Br catalyst shows high TOF numbers for the BHMF formation $\left(579.5 \mathrm{~h}^{-1}\right)$. However, the parent $\mathrm{Pd}$ catalyst exhibits a higher BHMTHF formation rate $\left(46.5 \mathrm{~h}^{-1}\right)$. The parent Pd catalyst is totally inactive in hydrodeoxygenation during the whole reaction in comparison with the $\mathrm{Br}$ modified catalyst. Thus, the role of $\mathrm{Br}$ can be assigned both to suppression of the ring hydrogenation pathway and activation of the hydrodeoxygenation route.

To confirm the recyclability of Pd-Br catalyst, the hydrodeoxygenation of HMF has been performed at $30{ }^{\circ} \mathrm{C}$ and 5 bar of $\mathrm{H}_{2}$ over the $\mathrm{Br}-\mathrm{Pd} / \mathrm{Al}_{2} \mathrm{O}_{3}$ catalyst in three consecutive cycles with intermediate separation of the catalyst (Figure 2). The catalyst demonstrates comparable activity in HMF transformation with a slight decrease in the 2 and 3 cycles, which could be explained by the loss of catalysts during separation. The selectivity curves are very similar for all three cycles with the 
same distribution of the products and high selectivity to DMF (>90\%) at high conversions. No catalyst deactivation was observed. Moreover, additional stability tests have been performed for 5 cycles at high conversion at ambient temperature (Figure S7, SI). Despite a slight decrease of conversion due to the loss of catalyst during separation, the $\mathrm{Pd}-\mathrm{Br}$ catalyst showed similar product selectivity, confirming the high stability of the $\mathrm{Pd}-\mathrm{Br}$ catalyst.

\subsection{Characterization of the Pd-Br catalysts}

The $\mathrm{Pd}-\mathrm{Br}$ catalysts have been studied further to identify the nature of the interaction of $\mathrm{Br}$ with the catalyst and nature of active sites for HMF hydrodeoxygenation.

First of all, the location of $\mathrm{Br}$ atoms was determined by TEM-EDS analysis. Due to the superposition of the main $\mathrm{Br}$ and $\mathrm{Al}$ edges in an EDS spectrum, $\mathrm{Br}-\mathrm{Pd} / \mathrm{SiO}_{2}$ with a similar promotion effect was selected as a model catalyst for EDS mapping analysis. EDS mapping clearly shows the preferential localization of $\mathrm{Br}$ on the surface of palladium nanoparticles (Figure 3). The signal of $\mathrm{Br}$ atoms (in blue) is localized at the same places as Pd (in green) indicating spatial coexistence of both elements and a possible modification of $\mathrm{Pd}$ surface by the presence of $\mathrm{Br}$ atoms. Selective area EDS analysis of $\mathrm{Br}-\mathrm{Pd} / \mathrm{SiO}_{2}$ also confirmed the localization of $\mathrm{Br}$ on $\mathrm{Pd}$, as the $\mathrm{Br}$ signal mostly appears on the Pd nanoparticles and not on the support (Figure S8, SI).

The amount of $\mathrm{Br}$ on the $\mathrm{Br}-\mathrm{Pd} / \mathrm{Al}_{2} \mathrm{O}_{3}$ catalysts was measured by XRF analysis and the results are summarized in Table 2. The amount of $\mathrm{Br}$ in the catalyst $(0.11$ wt. \%) is significantly lower in comparison with the amount of $\mathrm{Pd}$. 
CO-pulse chemisorption has been conducted to evaluate the amount of available surface Pd sites on the catalyst. Table 2 shows that the amount of adsorbed CO over the initial $\mathrm{Pd} / \mathrm{Al}_{2} \mathrm{O}_{3}$ catalyst is $0.16 \mathrm{mmol} / \mathrm{g}$, however, after pretreatment with $\mathrm{BrBen}$, the $\mathrm{CO}$ adsorption amount decreases to $0.059 \mathrm{mmol} / \mathrm{g}$. The dispersion of $\mathrm{Pd}\left(\mathrm{Pd}_{\mathrm{CO}} / \mathrm{Pd}\right)$ in the non-promoted catalyst corresponds to $33 \%$ according to $\mathrm{CO}$ adsorption. This decline of the $\mathrm{CO}$ adsorption demonstrates the modification of $\mathrm{Pd}$ surface with the $\mathrm{Br}$ atoms, which prevents the adsorption of $\mathrm{CO}$ on $\mathrm{Pd}$. The coverage of $\mathrm{Pd}$ by $\mathrm{Br}$ has been calculated by dividing the amount of $\mathrm{Br}(0.014 \mathrm{mmol} / \mathrm{g})$ by the amount of surface $\mathrm{Pd}(0.16 \mathrm{mmol} / \mathrm{g})$, which is equal to $8.7 \%$. Notably, the $\mathrm{Br}$ loading could be tuned by the Pd metal dispersion. As shown in Table S4, SI, Pd/C with higher metal dispersion $(40 \%)$ than $\mathrm{Pd} / \mathrm{Al}_{2} \mathrm{O}_{3}(33 \%)$ accumulates a higher amount of $\mathrm{Br}$ on the catalyst confirming the localization of $\mathrm{Br}$ on the $\mathrm{Pd}$ surface. Moreover, the coverage of $\mathrm{Br}$ on $\mathrm{Br}-\mathrm{Pd} / \mathrm{C}(18.4 \%)$ catalyst is significantly higher in comparison with $\mathrm{Br}-\mathrm{Pd} / \mathrm{Al}_{2} \mathrm{O}_{3}$, which could be ascribed to the presence of a higher fraction of defect sites over Pd nanoparticles on the C support. ${ }^{[44]}$

FTIR spectroscopy of CO adsorption has been used to identify the localization of Br. A set of $\mathrm{CO}$ absorption bands have been observed on non-promoted $\mathrm{Pd} / \mathrm{Al}_{2} \mathrm{O}_{3}$. The band at $2084 \mathrm{~cm}^{-1}$ with a shoulder at $2057 \mathrm{~cm}^{-1}$ is due to CO linearly adsorbed on defect sites of Pd nanoparticles presence at edges and corners. The intensive band at $1941 \mathrm{~cm}^{-1}$ is related to $\mathrm{CO}$ adsorbed on the Pd nanoparticles planes with bridge-bonds (Figure 4) ${ }^{[45]}$. The modification of $\mathrm{Pd}$ by $\mathrm{Br}$ leads to the almost complete disappearance of the peak at $2084 \mathrm{~cm}^{-1}$ with an obvious decrease in the intensity of 
the peaks attributed to CO adsorption over planes. Well-resolved peaks at $1973 \mathrm{~cm}^{-1}$ and $1934 \mathrm{~cm}^{-1}$ over $\mathrm{Br}-\mathrm{Pd} / \mathrm{Al}_{2} \mathrm{O}_{3}$ could be assigned to $\mathrm{CO}$ adsorbed on $\mathrm{Pd}(100)$ and (111) facets, respectively ${ }^{[45]}$. The less adsorption of CO on (100) facets and the defect sites could be explained by simplified hydrogenolysis of BrBen and deposition of $\mathrm{Br}$ over these low-coordination sites of Pd. Moreover, a small peak with a higher frequency at $2140 \mathrm{~cm}^{-1}$ is visible and assigned to $\mathrm{CO}$ bonded to $\mathrm{Pd}-\mathrm{Br}$ sites, where electronic deficient Pd heightens the vibrational frequency of adsorbed $\mathrm{CO}^{[46-47]}$.

The electronic state of $\mathrm{Pd}$ and $\mathrm{Br}$ in the $\mathrm{Br}-\mathrm{Pd} / \mathrm{Al}_{2} \mathrm{O}_{3}$ catalyst has been studied by XPS. Figure 5 demonstrates the $\mathrm{Pd} 3 \mathrm{~d}$ and $\mathrm{Br} 3 \mathrm{~d}$ core-level spectra of $\mathrm{Br}-\mathrm{Pd} / \mathrm{Al}_{2} \mathrm{O}_{3}$ before and after reaction in comparison with the parent $\mathrm{Pd} / \mathrm{Al}_{2} \mathrm{O}_{3}$. The $\mathrm{Pd} 3 \mathrm{~d}$ spectrum of $\mathrm{Pd} / \mathrm{Al}_{2} \mathrm{O}_{3}$ catalyst, as shown in Figure 5a, has two doublets with $\mathrm{BE}\left(\mathrm{Pd} 3 \mathrm{~d}_{5 / 2}\right)$ at $335.3 \mathrm{eV}$ and $336.6 \mathrm{eV}$ attributed to metallic $\mathrm{Pd}^{0}$ and $\mathrm{Pd}^{2+}(\mathrm{PdO})$, respectively ${ }^{[48]}$. Both of these states coexist on the surface with the dominant metallic state. Interestingly, a shift $(0.3 \mathrm{eV})$ of $\mathrm{Pd} 3 \mathrm{~d}$ peaks to higher $\mathrm{BE}$ for the $\mathrm{Br}-\mathrm{Pd} / \mathrm{Al}_{2} \mathrm{O}_{3}$ catalysts has been observed after modification by $\mathrm{Br}$. It can be attributed to the interaction of metallic $\mathrm{Pd}$ with $\mathrm{Br}$ adatoms with the electron withdrawal from $\mathrm{Pd}$ to electrophilic $\mathrm{Br}^{[49]}$. Signal of oxidized $\mathrm{Pd}^{2+}$ in $\mathrm{PdO}$ can be observed before and after modification by $\mathrm{Br}$ due to the partial oxidation of surface $\mathrm{Pd}$ atoms. Notably, an additional peak appears at much higher binding energy at $338.0 \mathrm{eV}$ in the Pd $3 \mathrm{~d}$ XPS spectrum after modification of the $\mathrm{Br}-\mathrm{Pd} / \mathrm{Al}_{2} \mathrm{O}_{3}$ catalyst. $\mathrm{PdBr}_{2}$ has a signal of $\mathrm{Pd}^{2+}$ with binding energy at $337.8 \mathrm{eV}$. The peak at higher binding energy at $338.0 \mathrm{eV}$ could be assigned to the presence of $\mathrm{PdBr}_{2}$ species adsorbed over the surface of metal 
nanoparticles.

For the $\mathrm{Br}-\mathrm{Pd} / \mathrm{Al}_{2} \mathrm{O}_{3}$ catalyst, the $\mathrm{Br} 3 \mathrm{~d}_{5 / 2}$ peak is located at $68.6 \mathrm{eV}$, which is lower than $69.1 \mathrm{eV}$ for $\mathrm{Br}^{-}$in $\mathrm{PdBr}_{2}$. The red-shift $(0.5 \mathrm{eV})$ indicates an increase in the electronic density in comparison with $\mathrm{PdBr}_{2}$ due to the transfer of electronic density from $\mathrm{Pd}$ metallic nanoparticles to $\mathrm{Br}$. The red shift of the $\mathrm{Br} 3 \mathrm{~d} 5 / 2$ XPS peak is consistent with the increase in the electron $\mathrm{BE}$ of $\mathrm{Pd}$ metal atoms due to the withdrawal of the electron density from palladium towards the bromine atoms. It has to be noted that the XPS spectra of $\mathrm{Pd}$ and $\mathrm{Br}$ of the $\mathrm{Br}-\mathrm{Pd} / \mathrm{Al}_{2} \mathrm{O}_{3}$ catalyst are not affected by conducting the reaction.

Pyridine adsorption has been carried out on non-promoted $\mathrm{Pd} / \mathrm{Al}_{2} \mathrm{O}_{3}$ and $\mathrm{Br}-\mathrm{Pd} / \mathrm{Al}_{2} \mathrm{O}_{3}$ to study the catalyst acidity in the absence and in the presence of $\mathrm{H}_{2}$ (Figure 6). In the absence of hydrogen, the spectra of Py adsorption are very similar. Both non-promoted $\mathrm{Pd} / \mathrm{Al}_{2} \mathrm{O}_{3}$ and $\mathrm{Br}-\mathrm{Pd} / \mathrm{Al}_{2} \mathrm{O}_{3}$ exhibit a peak at $1449 \mathrm{~cm}^{-1}$ attributed to the Lewis acid sites, which are probably present on the $\mathrm{Al}_{2} \mathrm{O}_{3}$ support ${ }^{[50]}$. Notably, there is no peak at $1540 \mathrm{~cm}^{-1}$ for both catalysts, which is related to the adsorption of pyridine over the Brønsted acid sites. In-situ pretreatment of $\mathrm{Br}-\mathrm{Pd} / \mathrm{Al}_{2} \mathrm{O}_{3}$ in $\mathrm{H}_{2}$ at $60^{\circ} \mathrm{C}$ at atmospheric pressure with subsequent adsorption of Py after hydrogen evacuation, leads to the appearance of a well-resolved peak at $1538 \mathrm{~cm}^{-1}$ indicating the generation of Brønsted acidity in the presence of hydrogen. It is worth mentioning that if hydrogen were still in the cell, Py has been hydrogenated leading to the complex spectrum (Figure $\mathbf{S 9}$, SI). Thus, the exposure of the $\mathrm{Br}-\mathrm{Pd} / \mathrm{Al}_{2} \mathrm{O}_{3}$ catalyst to hydrogen generates Brønsted acidity. This acidity is stable and does not disappear 
after the removal of hydrogen. The phenomenon is different from our previous data reported on the Pd catalyst treated by iodine, where the Brønsted acidity vanished after removing of $\mathrm{H}_{2}{ }^{[36]}$. This difference can be attributed to the higher electronegativity of bromine in comparison with iodine, which should result in the stronger stabilization of in-situ generated $\mathrm{H}^{+}$over the $\mathrm{Br}$ atoms. The same experiment over non-promoted $\mathrm{Pd} / \mathrm{Al}_{2} \mathrm{O}_{3}$ does not show any generation of the Brønsted acidity (Figure 6).

Moreover, the effect of $\mathrm{H}_{2} \mathrm{O}$ on the generation of Brønsted acidity has been studied by Py-FTIR. As shown in Figure S10, SI, there is no Brønsted acidity generation in the simultaneous presence of Pyridine and $\mathrm{H}_{2} \mathrm{O}$ over $\mathrm{Pd}-\mathrm{Br}$ catalyst. However, the addition of $\mathrm{H}_{2}$ in the FTIR cell results in the appearance of the Brønsted acidity. These results confirm the generation of Brønsted acidity by the dissociation of $\mathrm{H}_{2}$ to form $\mathrm{Pd}-\mathrm{Br}-\left(\mathrm{H}^{+}\right)$.

\subsection{Model reactions}

It is interesting to note that the presence of $\mathrm{Br}$ on the surface of $\mathrm{Pd}$ results in suppression of the hydrogenation of the aromatic ring in HMF. Considering that the hydrogenation of aromatic-rings is a moderately structure sensitive reaction ${ }^{[51]}$, the suppression of aromatic ring hydrogenation can be assigned to the electronic effect of $\mathrm{Br}$ over the Pd surface leading to a decrease of the electronic density over Pd with low homolytic hydrogenation activity. The strong electronic effect on aromatic rings hydrogenation has been confirmed in the literature ${ }^{[52-53]}$. In contrast, this catalyst 
provides high activity for heterolytic dissociation of $\mathrm{H}_{2}$ towards hydride and proton on the $\mathrm{Pd}-\mathrm{Br}$ sites. This results in the appearance of the Brønsted acidity and may favor the hydrogenation of polar functional groups ${ }^{[54-55]}$. To support these assumptions, additional model experiments over $\mathrm{Pd} / \mathrm{Al}_{2} \mathrm{O}_{3}$ and $\mathrm{Br}-\mathrm{Pd} / \mathrm{Al}_{2} \mathrm{O}_{3}$ have been performed. These model experiments include hydrogenation of DMF, 3-phenylpropanal and benzyl alcohol. The goal was to demonstrate selectivity of different sites over non-promoted and Br-promoted Pd nanoparticles for hydrogenation of furan ring, carbonyl group and hydrodeoxygenation of hydroxyl group, respectively.

Figure 7 demonstrates higher activity of the non-promoted $\mathrm{Pd} / \mathrm{Al}_{2} \mathrm{O}_{3}$ catalyst for hydrogenation of furan ring in DMF and carbonyl group in 3-phenylpropanal and almost zero activity for hydrodeoxygenation of benzyl alcohol to toluene. Modification by $\mathrm{Br}$ has changed dramatically the catalytic behavior with suppression of hydrogenation of aromatic ring in DMF. At the same time, the $\mathrm{Br}-\mathrm{Pd} / \mathrm{Al}_{2} \mathrm{O}_{3}$ catalyst showed high activity for hydrogenation of 3-phenylpropanal to 3-phenyl-1-propanol and hydrodeoxygenation of benzyl alcohol to toluene. The $\mathrm{Pd}-\mathrm{Br}$ catalyst seems to favor the hydrogenation of the polar carbonyl groups and deoxygenation. However, it exhibits extremely lower activity in the hydrogenation of low polarity aromatic rings. The high hydrodeoxygenation ability for benzyl alcohol to toluene over $\mathrm{Pd}-\mathrm{Br}$ catalyst has been further confirmed by the analysis of kinetic and activation energy of the reaction (Figure S11, SI). The reaction obeys first-order rate law. The activation energy for benzyl alcohol hydrodeoxygenation was estimated to be $38.7 \mathrm{~kJ} / \mathrm{mol}$ over initial $\mathrm{Pd} / \mathrm{Al}_{2} \mathrm{O}_{3}$ with a decrease to $1.3 \mathrm{~kJ} / \mathrm{mol}$ over $\mathrm{Br}-\mathrm{Pd} / \mathrm{Al}_{2} \mathrm{O}_{3}$ catalyst. This result 
confirms the high hydrodeoxygenation ability of $\mathrm{Pd}-\mathrm{Br}$ catalyst.

\subsection{Discussion}

Hydrogenation of HMF to DMF has been widely studied by different groups (Table 3). Almost for all catalysts the catalytic route for DMF synthesis passes through 3 steps: 1) Conversion of HMF to BHMF or methylfurfural (MFF), 2) hydrogenation of BHMF or MFF to MFA and finally 3) deoxygenation of MFA to $\mathrm{DMF}^{[56]}$. The scheme proposed during kinetic study of hydrodeoxygenation of HMF over $\mathrm{Pd}-\mathrm{Br}$ catalyst in agreement with the literature reported by Alexis $\mathrm{T}$. Bell et al. (Table 1) ${ }^{[57]}$.

However, this route is usually accompanied by different side reactions, which could be subdivided into two groups: hydrogenation of aromatic ring instead of the $\mathrm{C}=\mathrm{O}$ and $\mathrm{C}-\mathrm{OH}$ bonds and oligomerization of $\mathrm{HMF}$ at high temperature. Generally, the hydrogenation of the $\mathrm{C}=\mathrm{C}$ bonds is thermodynamically preferably than hydrogenation of $\mathrm{C}=\mathrm{O}$. However, the $\mathrm{C}=\mathrm{C}$ bond in furan ring is stabilized by aromatic conjugation, which makes the situation different ${ }^{[58]}$. It results in the formation of different by-products like MTHFA, BHMTF etc. The by-products formation can also lead to catalyst deactivation. Indeed, even heating of $\mathrm{HMF}$ to $100{ }^{\circ} \mathrm{C}$ in the presence of water leads to generation of humins ${ }^{[34]}$.

The catalytic performance of $\mathrm{Br}-\mathrm{Pd} / \mathrm{Al}_{2} \mathrm{O}_{3}$ has been compared with the most efficient catalytic systems in the literature. Table $\mathbf{3}$ shows two different types of catalysts that have been reported for the hydrogenation HMF to DMF. Metallic 
catalysts without acid promotions need high temperature for DMF production from HMF. For example, Román-Leshkov et al. integrated a $\mathrm{CuRu} / \mathrm{C}$ catalyst in the process of production of DMF from fructose ${ }^{[14]}$. A yield up to $71 \%$ in the liquid phase hydrogenolysis of HMF was obtained at $220{ }^{\circ} \mathrm{C}$ and 6.8 bar $\mathrm{H}_{2}$ pressure. The Pt-Co bimetallic on multi-walled carbon nanotubes (MWCNTs) catalyst needs a high temperature of up to $160{ }^{\circ} \mathrm{C}$ for this reaction $(>90 \%)^{[18]}$.

While pure metallic catalysts need high temperature for DMF production and often exhibit fast deactivation, the usage of metal-acid bifunctional catalytic systems could significantly promote the deoxygenation rate of HMF to DMF (Table 3, Entry 8-14) ${ }^{[24-33]}$. The conversion of HMF to DMF over metal-acid catalysts is performed by metallic sites responsible for hydrogenation of carbonyl groups, while the acid sites of support are required for $\mathrm{C}-\mathrm{OH}$ bond activation and simultaneous hydrogenolysis on metallic sites. The intimacy of metal and acid sites in the bifunctional catalysts seems to be primordial for deoxygenation. Insufficient contact between metal and acid sites limits the deoxygenation efficiency of HMF to DMF.

Up to date, the most active bifunctional metal-acid catalytic system for the HMF deoxygenation has been the combination of heterogeneous metal catalyst with homogenous acid (Table 3, Entry 12-14) ${ }^{[24-27]}$. In the presence of acetic acid, the yield of DMF increased from 0 to $85 \%$ over $\mathrm{Pd} / \mathrm{C}$ at $120{ }^{\circ} \mathrm{C}{ }^{[24]}$. Bimetallic $\mathrm{PdAu} / \mathrm{C}$ exhibited a significant yield of over $99 \%$ for selective hydrogenation of HMF toward DMF in the presence of homogeneous $\mathrm{HCl}$ at $60{ }^{\circ} \mathrm{C}{ }^{[25]}$. The homogenous acids provide intimacy of acid sites around the metal surface, which could protonate the 
substrate hydroxyl group and polarize the C-O bond and favor the cleavage of the C-O bond over $\mathrm{Pd}^{[58]}$. However, the addition of homogeneous organic or inorganic acid at the same time could result in the side self-condensation of HMF, which lowers the DMF productivity ${ }^{[34]}$. Besides, the presence of liquid acids in the reaction mixture leads to the corrosion of equipment.

The TOF numbers towards DMF formation were calculated based on the amount of active sites reported in the literature (Table 3). $\mathrm{Pd}-\mathrm{Br}$ sites exhibited higher activity to $\mathrm{DMF}\left(\mathrm{TOF}=181.7 \mathrm{~h}^{-1}\right)$ than most of the catalysts from the literature.

Thus, the elaboration of efficient catalysts for deoxygenation of biomass-derived compounds faces the following dilemma. Heterogeneous metal catalysts with acidic support do not have require metal-acid intimacy, while the combination of the metal catalysts with homogenous acid suffers from the side-reactions and corrosion issues. Our results demonstrate that the supported bifunctional metal catalysts promoted with bromine (Table 3) exhibit several advantages:

$\checkmark$ Hydrogenation at ambient temperature;

$\checkmark$ High-selectivity due to only hydrogenation of the $\mathrm{C}=\mathrm{O}$ bonds;

$\checkmark$ High-efficiency due to simultaneous activation and hydrogenolysis of C-OH bonds over metal and acid sites located in close proximity of metal palladium nanoparticles

$\checkmark \quad$ Heterogenization of the catalyst and easy separation of the catalyst and reaction products.

Indeed, heterolytic dissociation of hydrogen over the $\mathrm{Pd}-\mathrm{Br}$ sites should favor 
hydrogenation of the polar $\mathrm{C}=\mathrm{O}$ and $\mathrm{C}-\mathrm{OH}$ groups and should hinder hydrogenation of non-polar $\mathrm{C}=\mathrm{C}$ bonds as demonstrated in the model reactions (Figure 7). At the same time, the generation of Brønsted acid sites over $\mathrm{Pd}-\mathrm{Br}$ sites simplifies protonation and hydrogenolysis of the BHMF alcohol with the direct generation of DMF. Thus, Pd-Br catalyst has dual metal-acidic properties and can be used for direct deoxygenation of biomass-derived alcohols and aldehydes. The conventional bifunctional catalysts such as metal-zeolite or metal oxide composites contain metal sites over metal nanoparticles and acid sites over the zeolite or oxide support. The metal and acid sites in these catalysts are often sterically separated and suffer from insufficient intimacy. Different to previously developed metal-acid bifunctional catalysts, the $\mathrm{Pd}-\mathrm{Br}$ systems have both metal and acid sites located on the surface of the same metal nanoparticles. This results in the unique intimacy of metal and acid sites and in the spectacular enhancement of the catalytic performance and more particularly the reaction selectivity.

\section{Conclusion}

In this paper, an efficient $\mathrm{Pd}-\mathrm{Br}$ bifunctional catalyst with intimate metal and acid sites, which are both localized over the same metal nanoparticles, was developed and exhibited extremely high yield (96\%) to DMF from $\mathrm{HMF}$ at ambient temperature. The promotion with bromine results in double effect on the catalytic performance. On the one hand, it tunes the hydrogenation activity of Pd active sites. On the other hand, the promotion bromine creates Brønsted acid sites, which are situated in extremely close proximity to the metal sites. The adsorbed $\mathrm{Br}$ atoms on the $\mathrm{Pd}$ surface can 
prevent the hydrogenation of furan-ring, while the hydrogenation of carbonyl groups is not affected. The formed $\mathrm{Pd}-\mathrm{Br}$ sites on the $\mathrm{Pd}$ surface provide heterolytic dissociation of $\mathrm{H}_{2}$ for deoxygenation of the hydroxyl groups to DMF. To summarize, this paper describes design of a new type of bifunctional catalysts with enhanced intimacy of metal and acid sites. It deepens the understanding of how halogens can be used for the modification of metal surface for the generation of new types of active sites for activation of hydrogen in a heterolytic way with generation of the Brønsted acidity.

\section{AUTHOR INFORMATION}

\section{Corresponding Author}

Andrei Khodakov: E-mail:andrei.khodakov@univ-lille.fr;

Unité de Catalyse et de Chimie du Solide

UMR 8181 CNRS, Ecole Centrale de Lille, Université de Lille

Bât. C3, 59655 Villeneuve d'Ascq, France

Vitaly Ordormsky: E-mail:vitaly.ordomsky@univ-lille.fr

E2P2L, UMI 3464 CNRS-Solvay, 3966 Jin Du Rd., 201108 Shanghai, China

\section{Author Contributions}

The manuscript was written through contributions of all authors. All authors have given approval to the final version of the manuscript.

\section{ASSOCIATED CONTENT}


Supporting Information. Description of side-products; GC and GC-MS images; IR spectrum; TEM images; Supplementary catalytic test; Kinetic studies.

\section{ACKNOWLEDGMENT}

The authors thank Solvay and Lille University for stipend for the $\mathrm{PhD}$ research of D.W. and financial support of this work. 
<smiles>O=Cc1ccc(CO)o1</smiles><smiles>OCC1CCC(CO)O1</smiles><smiles>O=Cc1ccc(CO)o1</smiles>

$30^{\circ} \mathrm{C}$<smiles>Cc1ccc(C)o1</smiles>
96\% yield
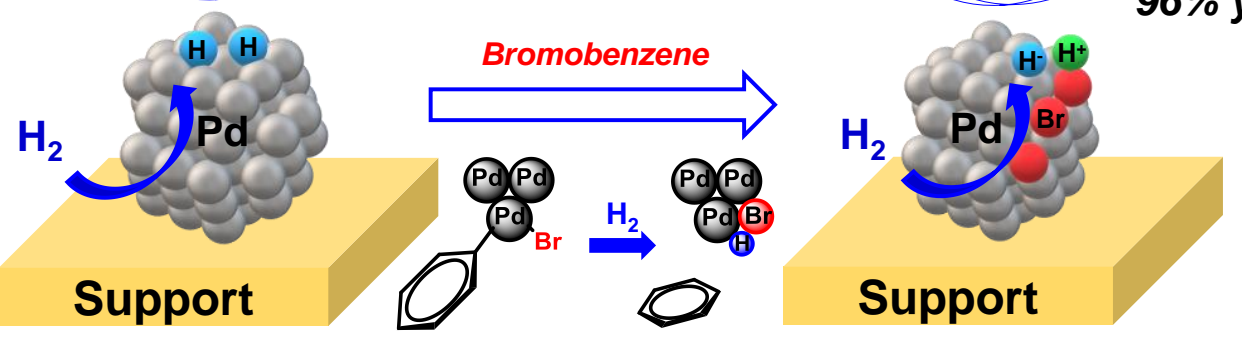

Scheme 1. HMF deoxygenation over Pd-Br catalyst via heterolytic dissociation of hydrogen. 


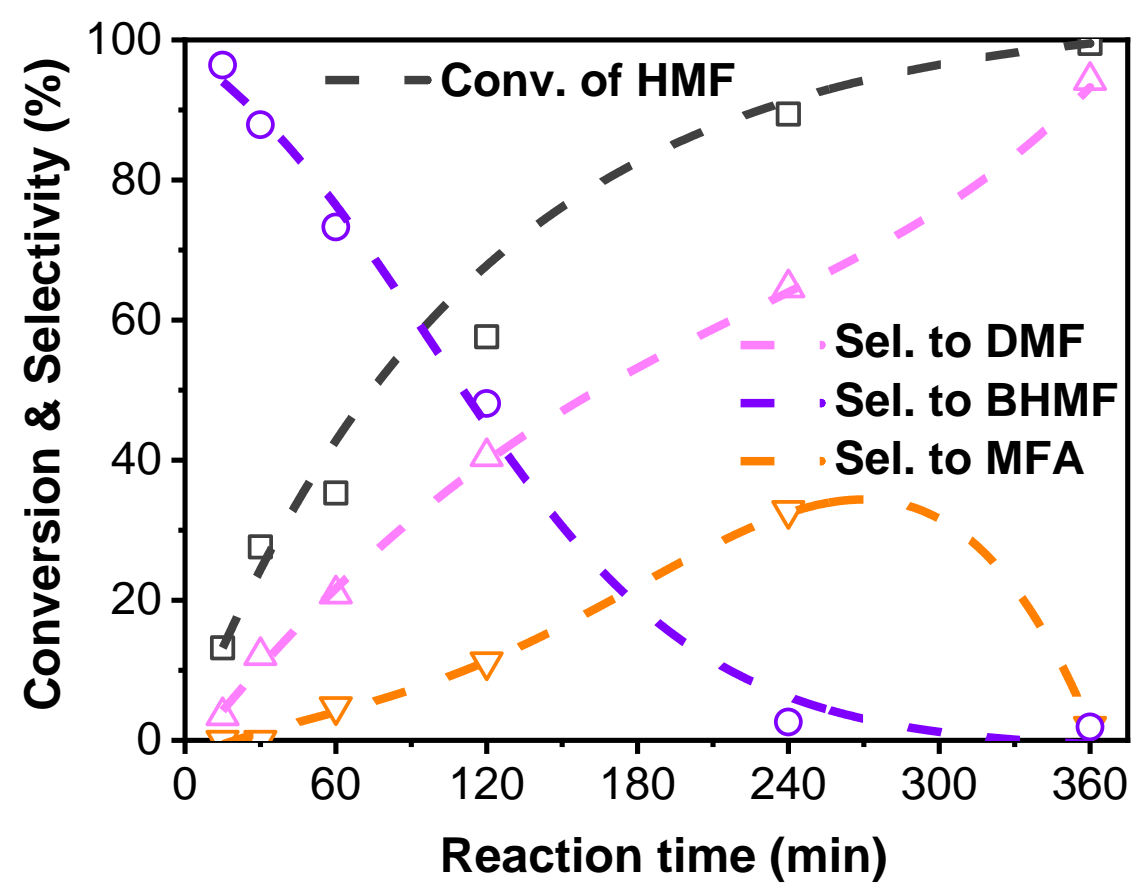

Figure 1. Kinetics of hydrogenation of $\mathrm{HMF}$ over $\mathrm{Br}-\mathrm{Pd} / \mathrm{Al}_{2} \mathrm{O}_{3}$. Reaction conditions:

$50 \mathrm{mg}$ of $\mathrm{Br}-\mathrm{Pd} / \mathrm{Al}_{2} \mathrm{O}_{3}, 100 \mathrm{mg}$ of $\mathrm{HMF}, 5 \mathrm{~g}$ of $\mathrm{THF}, 30^{\circ} \mathrm{C}, 5 \mathrm{bar} \mathrm{H}_{2}$. 
(a)

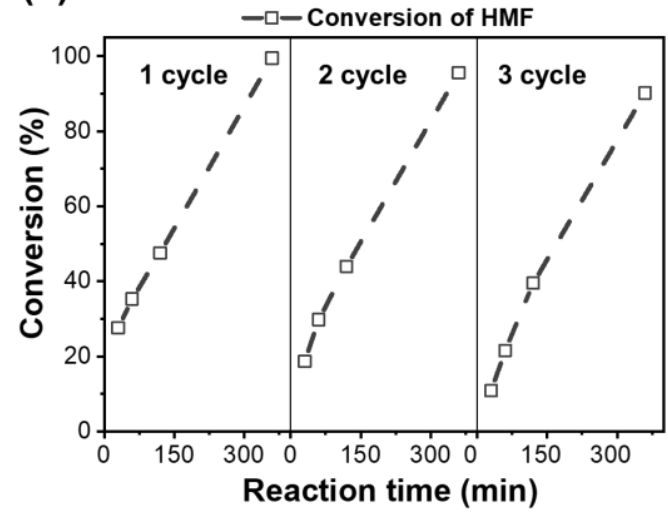

(b)

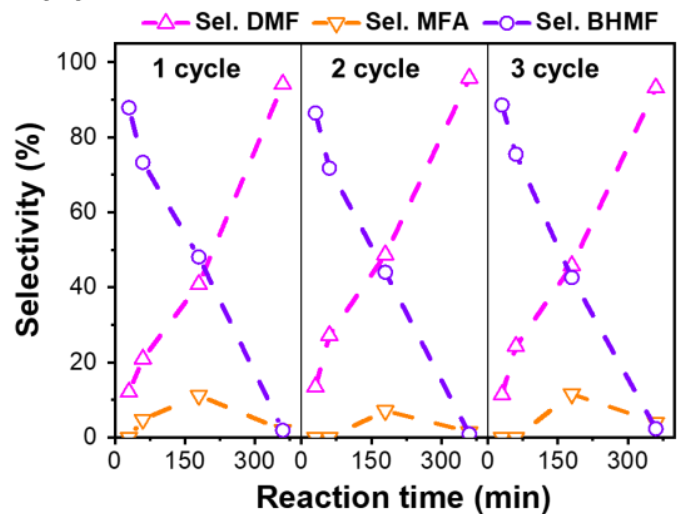

Figure 2. Evolution of conversion (a) and selectivity (b) for the first 3 cycles with reaction time. Reaction conditions: $50 \mathrm{mg} \mathrm{Br}-\mathrm{Pd} / \mathrm{Al}_{2} \mathrm{O}_{3}, 100 \mathrm{mg} \mathrm{HMF}, 5 \mathrm{~g} \mathrm{THF}, 30^{\circ} \mathrm{C}$, 5 bar $\mathrm{H}_{2}$. 


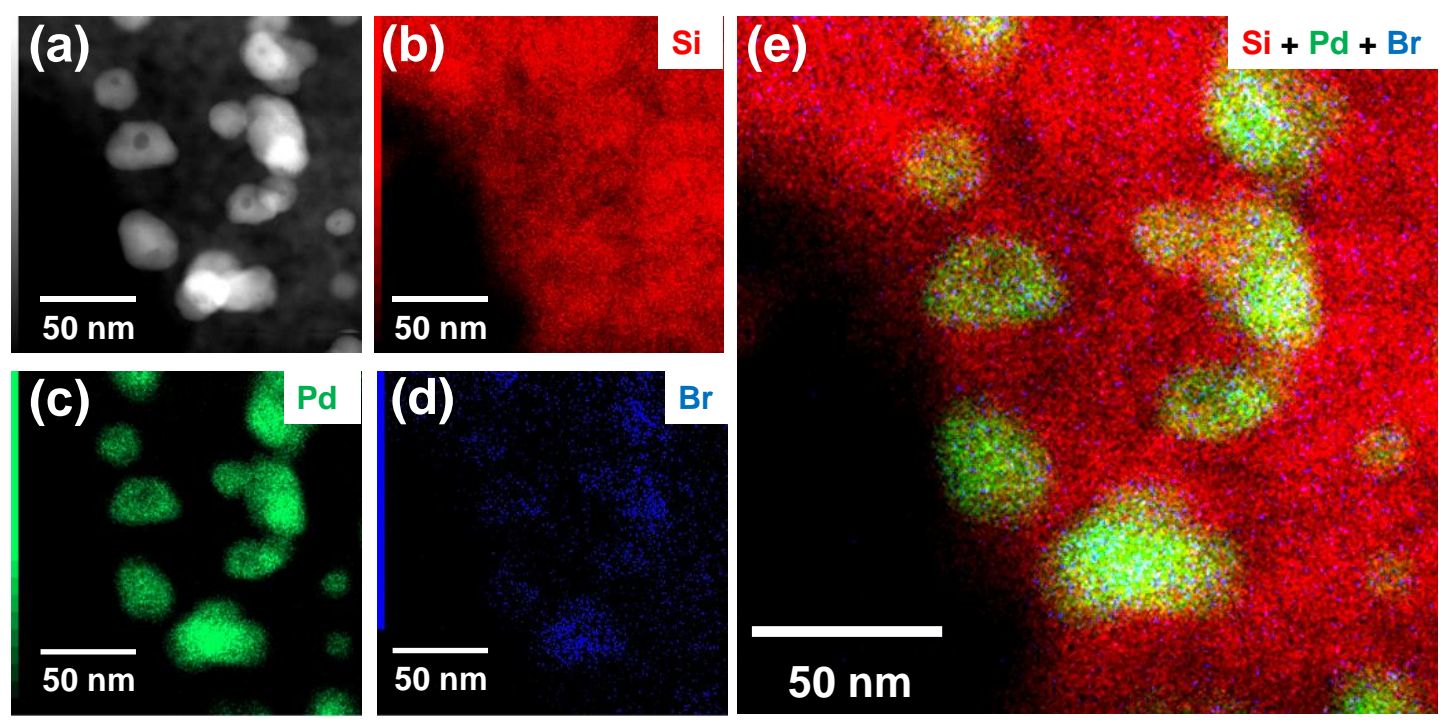

Figure 3. TEM-EDS analysis (a) STEM image and (b-e) corresponding EDS elemental maps of $\mathrm{Br}-\mathrm{Pd} / \mathrm{SiO} \mathrm{O}_{2}$ catalyst. 


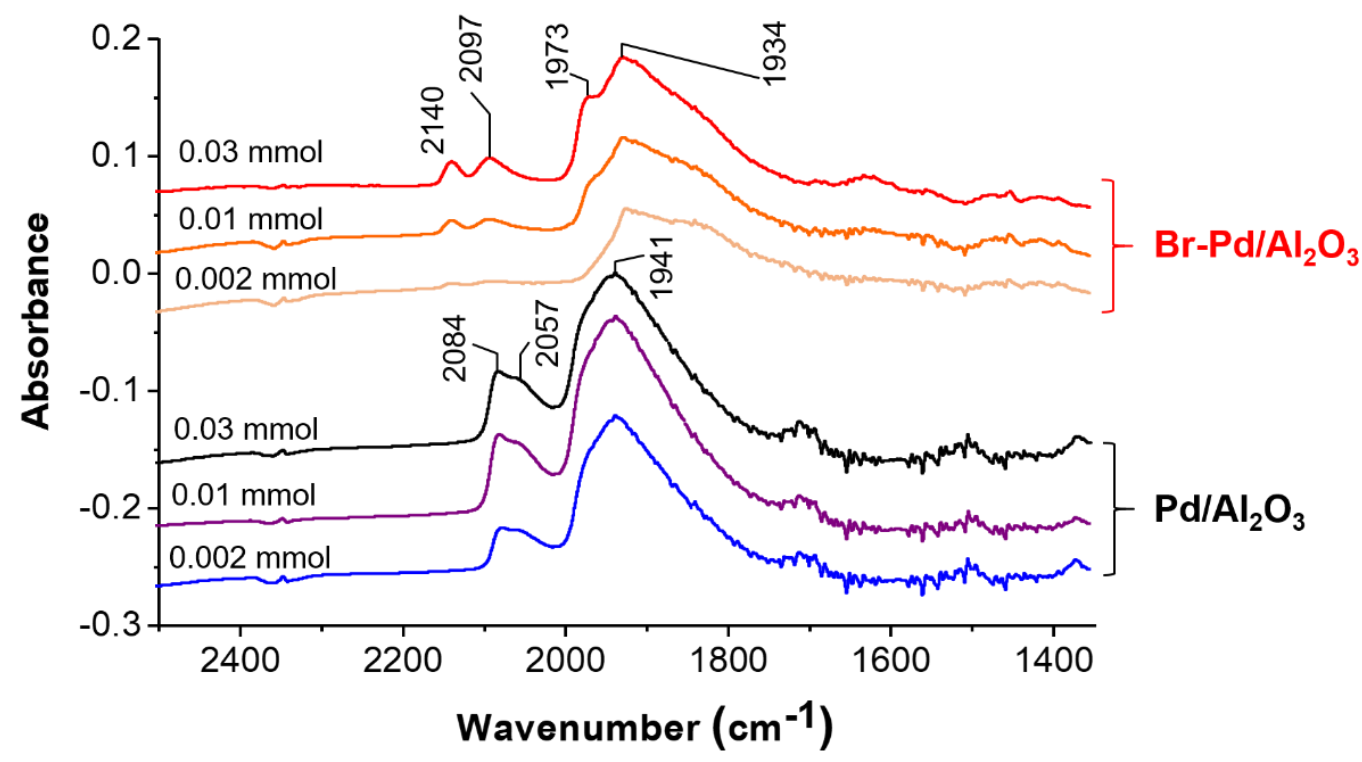

Figure 4. $\mathrm{CO}$-FTIR for $\mathrm{Pd} / \mathrm{Al}_{2} \mathrm{O}_{3}$ and $\mathrm{Br}-\mathrm{Pd} / \mathrm{Al}_{2} \mathrm{O}_{3}$ 
(a)

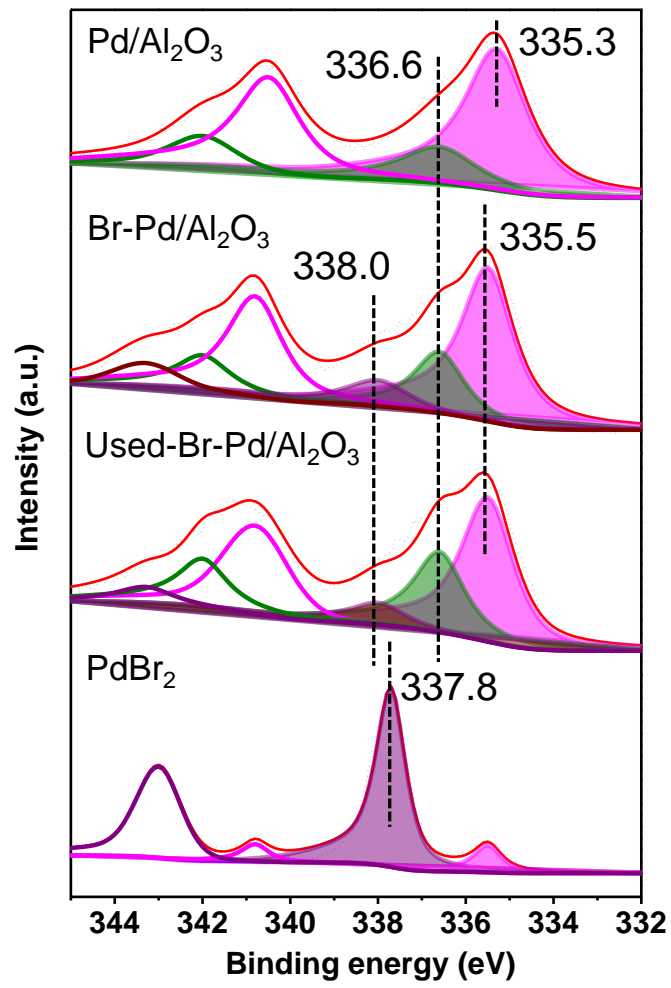

(b)

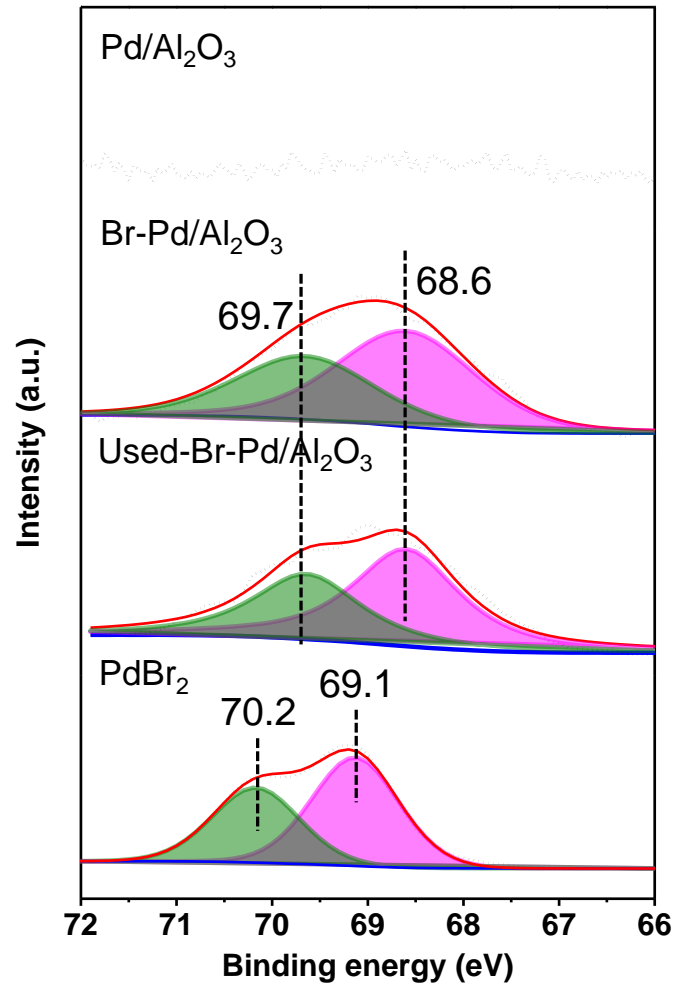

Figure 5. XPS (a) $\mathrm{Pd} 3 d$ and (b) $\mathrm{Br} 3 d$ core level spectra of $\mathrm{Pd} / \mathrm{Al} l_{2} \mathrm{O}_{3}, \mathrm{Br}-\mathrm{Pd} / \mathrm{Al} l_{2} \mathrm{O}_{3}$, and $\mathrm{Br}-\mathrm{Pd} / \mathrm{Al}_{2} \mathrm{O}_{3}$ after reaction. 


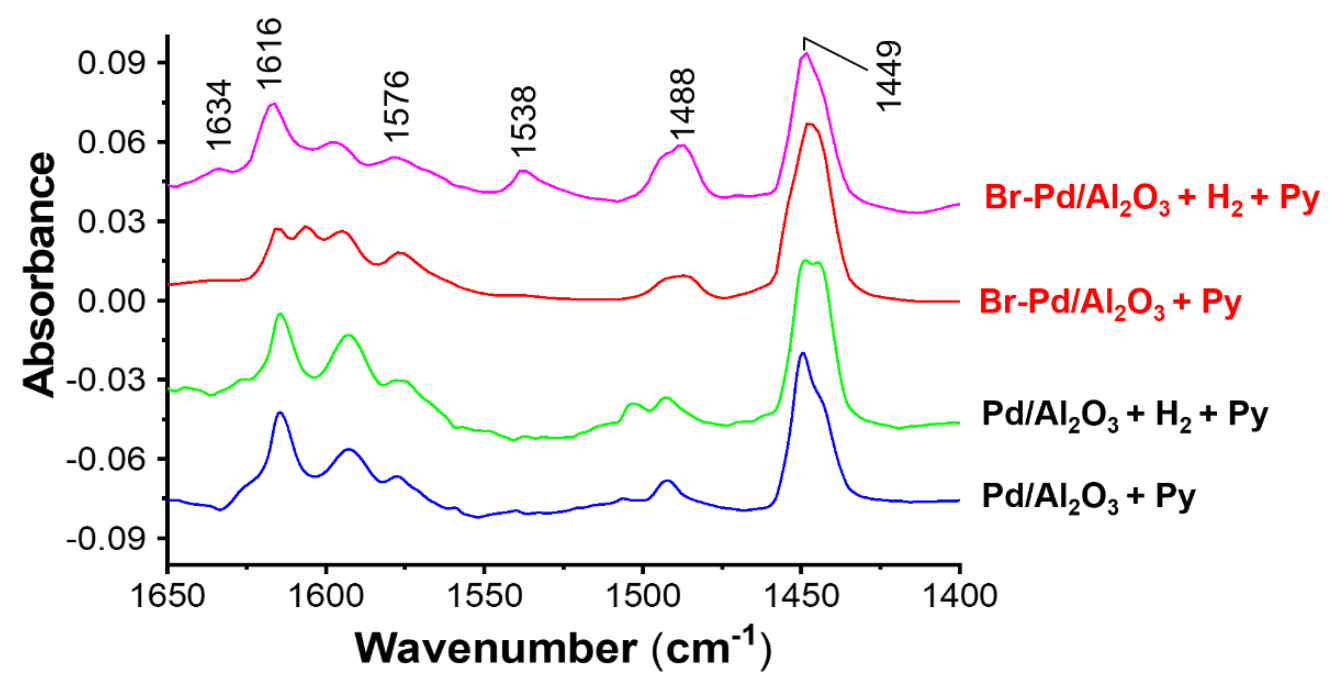

Figure 6. Pyridine-FTIR for $\mathrm{Pd} / \mathrm{Al}_{2} \mathrm{O}_{3}$ and $\mathrm{Br}-\mathrm{Pd} / \mathrm{Al}_{2} \mathrm{O}_{3}$ with and without hydrogen pre-treatment. 


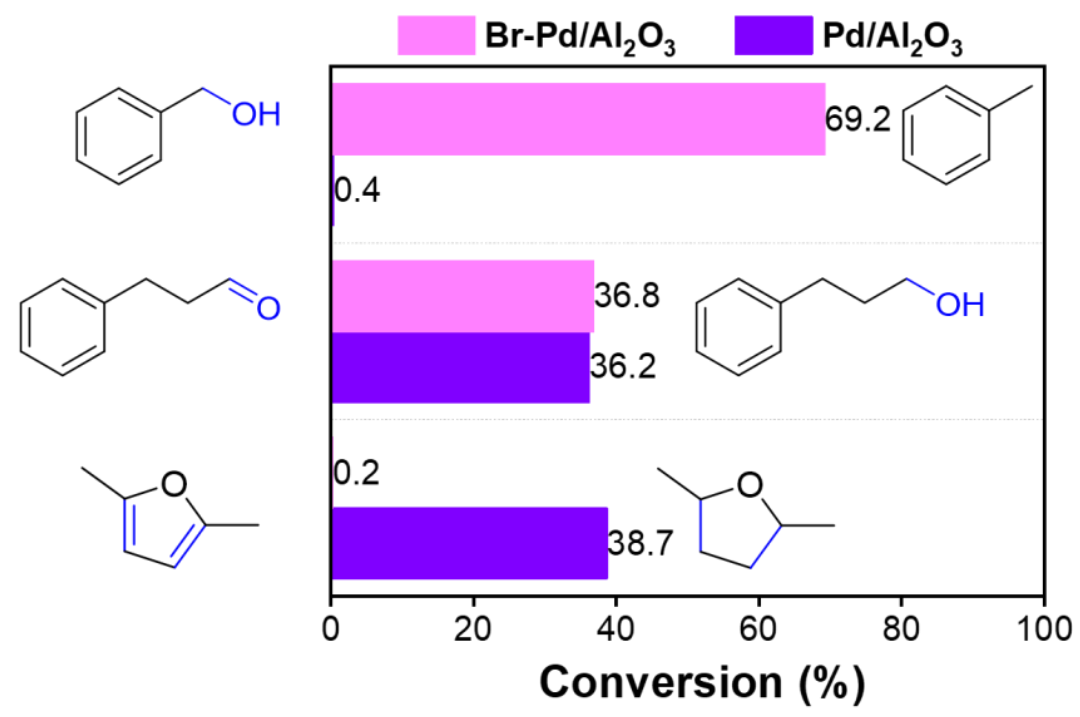

Figure 7. Model reactions of hydrogenation of DMF, 3-phenylpropanal, and benzyl alcohol over $\mathrm{Pd} / \mathrm{Al}_{2} \mathrm{O}_{3}$ and $\mathrm{Br}-\mathrm{Pd} / \mathrm{Al}_{2} \mathrm{O}_{3}$. Reaction conditions: $50 \mathrm{mg}$ of catalyst, 100 mg reactant, $5 \mathrm{~g}$ of THF, DMF hydrogenation: $60^{\circ} \mathrm{C}, 20 \mathrm{bar} \mathrm{H}_{2}, 1 \mathrm{~h}$; 3-phenylropanal hydrogenation: $30^{\circ} \mathrm{C}, 5$ bar $\mathrm{H}_{2}, 30 \mathrm{~min}$; Benzyl alcohol deoxygenation: $30^{\circ} \mathrm{C}, 5$ bar $\mathrm{H}_{2}, 15 \mathrm{~min}$. 
Table 1. Conversion of HMF over palladium catalysts under different conditions. Unless stated otherwise, the reaction conditions were as follows: $50 \mathrm{mg}$ catalyst, 10

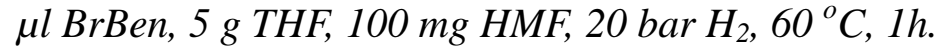

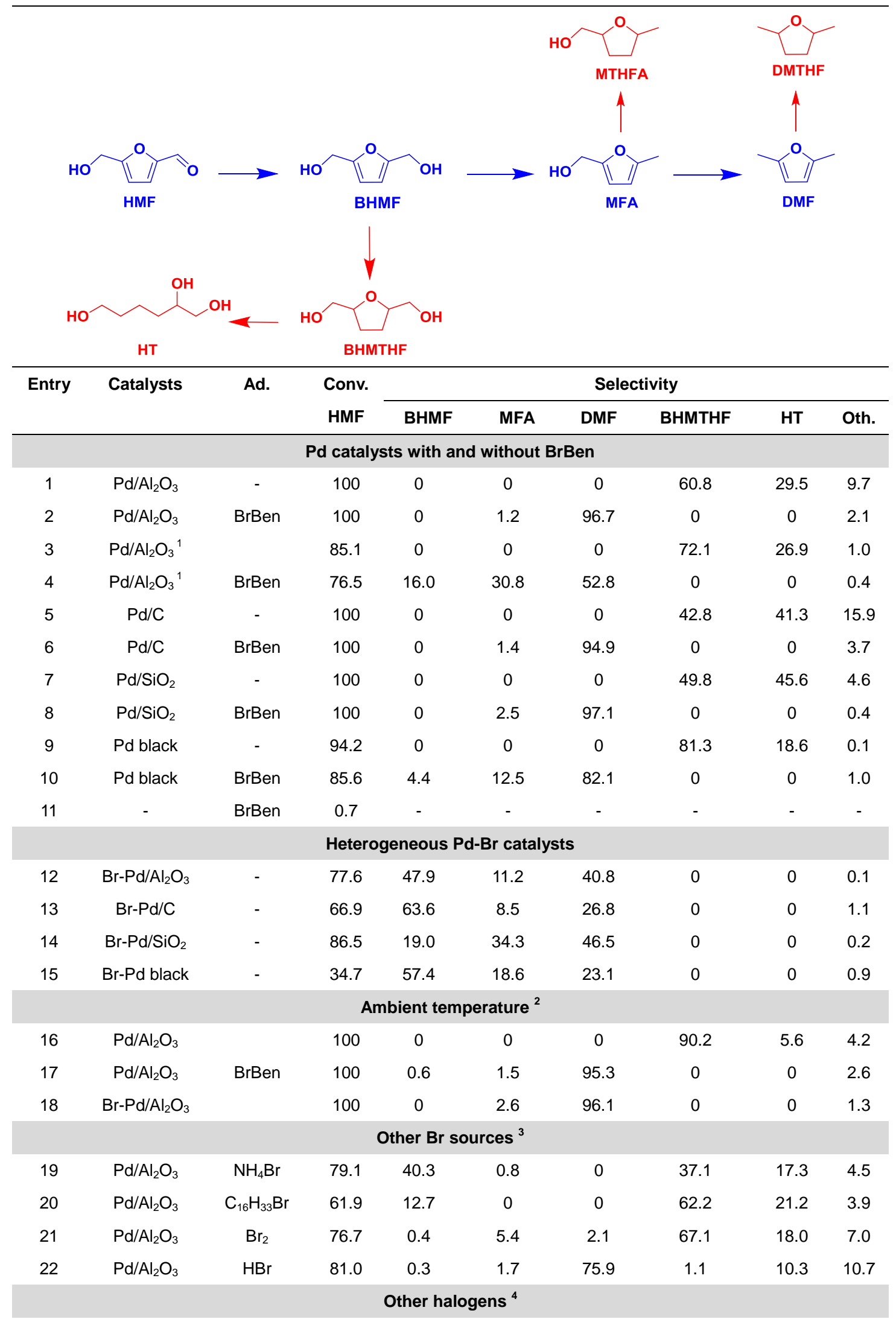




\begin{tabular}{lllllccccc}
23 & $\mathrm{Pd} / \mathrm{Al}_{2} \mathrm{O}_{3}$ & $\mathrm{ClBen}$ & 100 & 1.2 & 15.4 & 30.1 & 19.7 & 25.0 & 8.6 \\
24 & $\mathrm{Pd} / \mathrm{Al}_{2} \mathrm{O}_{3}$ & IBen & 0.8 & - & - & - & - & - & - \\
\hline
\end{tabular}

1. The reactions were performed for $30 \mathrm{~min}$.

2. The reaction was performed at $30{ }^{\circ} \mathrm{C}$ with 5 bars of external $\mathrm{H}_{2}$ pressure for 6 hours.

3. $15 \mathrm{mg} \mathrm{NH}_{4} \mathrm{Br}, 15 \mathrm{mg} \mathrm{C}_{16} \mathrm{H}_{33} \mathrm{Br}, 5 \mathrm{mg} \mathrm{Br}_{2}$, or $5 \mathrm{mg} \mathrm{HBr}$ were added to the reaction mixture, respectively.

4. CIBen and IBen were added for $10 \mu \mathrm{l}$ in the reaction mixture, respectively. 
Table 2. Summary of the results obtained from the characterizations of $\mathrm{Pd} / \mathrm{Al}_{2} \mathrm{O}_{3}$ and $\mathrm{Br}-\mathrm{Pd} / \mathrm{Al}_{2} \mathrm{O}_{3}$

\begin{tabular}{ccccc}
\hline Catalyst & Element analysis $(\mathbf{w t}$ \%) & & $\begin{array}{c}\mathrm{Br} \text { amount } \\
(\mathbf{m m o l} / \mathbf{g})\end{array}$ & $\begin{array}{c}\text { CO amount } \\
(\mathbf{m m o l} / \mathbf{g})\end{array}$ \\
\cline { 2 - 4 } & $\mathbf{P d}$ & $\mathrm{Br}$ & 0 & 0.16 \\
\hline $\mathrm{Pd} / \mathrm{Al}_{2} \mathrm{O}_{3}$ & 4.7 & 0 & 0.014 & 0.059 \\
\hline $\mathrm{Br}-\mathrm{Pd} / \mathrm{Al}_{2} \mathrm{O}_{3}$ & 5.1 & 0.11 & 0.14 \\
\hline
\end{tabular}


Table 3. Hydrodeoxygenation of HMF to DMF over various catalytic systems.

\begin{tabular}{|c|c|c|c|c|c|c|c|}
\hline \multirow{4}{*}{ Entry } & \multirow{4}{*}{ Catalyst } & \multicolumn{2}{|c|}{ Conditions } & \multicolumn{2}{|c|}{ Results } & \multirow[b]{2}{*}{ TOF $^{1}$} & \multirow[b]{2}{*}{ Ref } \\
\hline & & \multirow{3}{*}{ Solvent } & \multirow{3}{*}{$\mathbf{T},{ }^{\circ} \mathrm{C}$} & HMF & DMF & & \\
\hline & & & & & & & \\
\hline & & & & Conv., \% & Sel., \% & $h^{-1}$ & \\
\hline \multirow{3}{*}{1} & & & & & & & This \\
\hline & $\mathrm{Br}-\mathrm{Pd} / \mathrm{Al}_{2} \mathrm{O}_{3}$ & THF & 30 & 100 & 96.1 & 181.7 & \\
\hline & & & & & & & work \\
\hline \multicolumn{8}{|c|}{ Metal catalysts } \\
\hline 2 & $\mathrm{CuRu} / \mathrm{C}$ & 1-butanol & 220 & 100 & 79 & - & 14 \\
\hline 3 & $\mathrm{Ru} / \mathrm{C}$ & isopropanol & 190 & 100 & 80 & 11.5 & 19 \\
\hline 4 & $\mathrm{Ni} / \mathrm{SBA}-15$ & Dioxane & 180 & 95 & 74.2 & - & 22 \\
\hline 5 & CoCu@C & Ethanol & 180 & 100 & 99.4 & - & 23 \\
\hline 6 & $\mathrm{PtCo} / \mathrm{MWCNTs}$ & 1-butanol & 160 & 100 & 92.3 & 24.7 & 18 \\
\hline 7 & $\mathrm{Ru} / \mathrm{CNT}$ & Dioxane & 150 & 97 & 86.1 & 472.4 & 20 \\
\hline \multicolumn{8}{|c|}{ Bifunctional metal-acid catalysts } \\
\hline 8 & $\mathrm{Pd} / \mathrm{C} / \mathrm{Zn}$ & THF & 150 & 100 & 85 & 70.2 & 33 \\
\hline 9 & $\mathrm{Ru} / \mathrm{Co}_{3} \mathrm{O}_{4}$ & THF & 130 & 100 & 93.4 & - & 28 \\
\hline 10 & NiSi-PS & Dioxane & 130 & 100 & 72.9 & 101.5 & 30 \\
\hline \multirow{3}{*}{11} & $\mathrm{Pd}-\mathrm{Cs}_{2.5} \mathrm{H}_{0.5} \mathrm{PW}_{12} \mathrm{O}_{40}$ & & & & & & \\
\hline & & THF & 90 & 98 & 80.6 & 10.8 & 29 \\
\hline & /K-10 clay & & & & & & \\
\hline \multirow{3}{*}{12} & & $\mathrm{H}_{2} \mathrm{O}$-Dixoan & & & & & \\
\hline & $\mathrm{Pd} / \mathrm{C}+$ Acetic acid & & 120 & 95 & 89.5 & 8.5 & 24 \\
\hline & & e & & & & & \\
\hline 13 & $\mathrm{Pd} / \mathrm{C}+\mathrm{HCl}$ & THF & 60 & 99 & 100 & - & 25 \\
\hline 14 & $\mathrm{PdAu} / \mathrm{C}+\mathrm{HCl}$ & THF & 60 & 99 & 100 & - & 25 \\
\hline
\end{tabular}




\section{Reference}

[1] Wheeldon, I.; Minteer, S. D.; Banta, S.; Barton, S. C.; Atanassov, P.; Sigman, M., Substrate Channelling as An Approach to Cascade Reactions. Nat. Chem. 2016, 8 (4), 299-309.

[2] Lohr, T. L.; Li, Z.; Marks, T. J., Thermodynamic Strategies for C-O Bond Formation and Cleavage via Tandem Catalysis. Acc. Chem. Res. 2016, 49 (5), 824-858.

[3] Wu, X.; Cruz, F. A.; Lu, A.; Dong, V. M., Tandem Catalysis: Transforming Alcohols to Alkenes by Oxidative Dehydroxymethylation. J. Am. Chem. Soc. 2018, 140 (32), 10126-10130.

[4] Liu, H.; Jiang, T.; Han, B.; Liang, S.; Zhou, Y., Selective Phenol Hydrogenation to Cyclohexanone over A Dual Supported Pd-Lewis Acid Catalyst. Science 2009, 326 (5957), $1250-1252$.

[5] Konwar, L. J.; Maki-Arvela, P.; Mikkola, J. P., $\mathrm{SO}_{3} \mathrm{H}-$ Containing Functional Carbon Materials: Synthesis, Structure, and Acid Catalysis. Chem. Rev. 2019, 119 (22), 11576-11630.

[6] Cheng, K.; Zhou, W.; Kang, J.; He, S.; Shi, S.; Zhang, Q.; Pan, Y.; Wen, W.; Wang, Y., Bifunctional Catalysts for One-Step Conversion of Syngas into Aromatics with Excellent Selectivity and Stability. Chem 2017, 3 (2), 334-347.

[7] Chen, S.; Wojcieszak, R.; Dumeignil, F.; Marceau, E.; Royer, S., How Catalysts and Experimental Conditions Determine the Selective Hydroconversion of Furfural and 5-Hydroxymethylfurfural. Chem. Rev. 2018, 118 (22), 11023-11117.

[8] Xu, C.; Paone, E.; Rodriguez-Padron, D.; Luque, R.; Mauriello, F., Recent Catalytic Routes for The Preparation and The Upgrading of Biomass Derived Furfural and 5-Hydroxymethylfurfural. Chem. Soc. Rev. 2020, 49 (13), 4273-4306.

[9] Pang, J.; Sun, J.; Zheng, M.; Li, H.; Wang, Y.; Zhang, T., Transition Metal Carbide Catalysts for Biomass Conversion: A Review. Appl. Catal. B 2019, 254, 510-522.

[10] Ordomsky, V. V.; Sushkevich, V. L.; Schouten, J. C.; van der Schaaf, J.; Nijhuis, T. A., Glucose Dehydration to 5-Hydroxymethylfurfural over Phosphate Catalysts. J. Catal. 2013, 300, 37-46.

[11] Wang, J.; Wei, Q.; Ma, Q.; Guo, Z.; Qin, F.; Ismagilov, Z. R.; Shen, W., Constructing Co@N-doped Graphene Shell Catalyst via Mott-Schottky Effect for Selective Hydrogenation of 5-Hydroxylmethylfurfural. Appl. Catal. B 2020, 263. 118339.

[12] Ordomsky, V. V.; van der Schaaf, J.; Schouten, J. C.; Nijhuis, T. A., The Effect of Solvent Addition on Fructose Dehydration to 5-Hydroxymethylfurfural in Biphasic System over Zeolites. J. Catal. 2012, 287, 68-75.

[13] Sudarsanam, P.; Peeters, E.; Makshina, E. V.; Parvulescu, V. I.; Sels, B. F., Advances in Porous and Nanoscale Catalysts for Viable Biomass Conversion. Chem. Soc. Rev. 2019, 48 (8), 2366-2421.

[14] Roman-Leshkov, Y.; Barrett, C. J.; Liu, Z. Y.; Dumesic, J. A., Production of Dimethylfuran for Liquid Fuels from Biomass-derived Carbohydrates. Nature 2007, 447 (7147), 982-985.

[15] Tao, L.; Yan, T.-H.; Li, W.; Zhao, Y.; Zhang, Q.; Liu, Y.-M.; Wright, M. M.; Li, Z.-H.; He, H.-Y.; Cao, Y., Toward an Integrated Conversion of 5-Hydroxymethylfurfural and Ethylene for the Production of Renewable $p$-Xylene. Chem 2018, 4 (9), 2212-2227.

[16] Rohling, R. Y.; Tranca, I. C.; Hensen, E. J. M.; Pidko, E. A., Mechanistic Insight into the [4 + 
2] Diels-Alder Cycloaddition over First Row $d$-Block Cation-Exchanged Faujasites. ACS Catal. 2019, 9 (1), 376-391.

[17] Stadler, B. M.; Wulf, C.; Werner, T.; Tin, S.; de Vries, J. G., Catalytic Approaches to Monomers for Polymers Based on Renewables. ACS Catal. 2019, 9 (9), 8012-8067.

[18] Wang, X.; Liu, Y.; Liang, X., Hydrogenolysis of 5-Hydroxymethylfurfural to 2,5-Dimethylfuran over Supported Pt-Co Bimetallic Catalysts under Mild Conditions. Green Chem. 2018, 20 (12), 2894-2902.

[19] Jae, J.; Zheng, W.; Lobo, R. F.; Vlachos, D. G., Production of Dimethylfuran from Hydroxymethylfurfural Through Catalytic Transfer Hydrogenation with Ruthenium Supported on Carbon. ChemSusChem 2013, 6 (7), 1158-1162.

[20] Priecel, P.; Endot, N. A.; Carà, P. D.; Lopez-Sanchez, J. A., Fast Catalytic Hydrogenation of 2,5-Hydroxymethylfurfural to 2,5-Dimethylfuran with Ruthenium on Carbon Nanotubes. Ind. Eng. Chem. Res. 2018, 57 (6), 1991-2002.

[21] Jin, Z.; Yi, X.; Wang, L.; Xu, S.; Wang, C.; Wu, Q.; Wang, L.; Zheng, A.; Xiao, F.-S., Metal-Acid Interfaces Enveloped in Zeolite Crystals for Cascade Biomass Hydrodeoxygenation. Appl. Catal. B 2019, 254, 560-568.

[22] Chen, S.; Ciotonea, C.; De Oliveira Vigier, K.; Jérôme, F.; Wojcieszak, R.; Dumeignil, F.; Marceau, E.; Royer, S., Hydroconversion of 5-Hydroxymethylfurfural to 2,5-Dimethylfuran and 2,5-Dimethyltetrahydrofuran over Non-Promoted Ni/SBA-15. ChemCatChem 2020, 12 (7), 2050-2059.

[23] Chen, B.; Li, F.; Huang, Z.; Yuan, G., Carbon-Coated Cu-Co Bimetallic Nanoparticles as Selective and Recyclable Catalysts for Production of Biofuel 2,5-Dimethylfuran. Appl. Catal. B 2017, 200, 192-199.

[24] Mitra, J.; Zhou, X.; Rauchfuss, T., Pd/C-Catalyzed Reactions of HMF: Decarbonylation, Hydrogenation, and Hydrogenolysis. Green Chem. 2015, 17 (1), 307-313.

[25] Nishimura, S.; Ikeda, N.; Ebitani, K., Selective Hydrogenation of Biomass-Derived 5-Hydroxymethylfurfural (HMF) to 2,5-Dimethylfuran (DMF) under Atmospheric Hydrogen Pressure over Carbon Supported PdAu Bimetallic Catalyst. Catal. Today 2014, 232, 89-98.

[26] Chatterjee, M.; Ishizaka, T.; Kawanami, H., Hydrogenation of 5-Hydroxymethylfurfural in Supercritical Carbon Dioxide-Water: A Tunable Approach to Dimethylfuran Selectivity. Green Chem. 2014, 16 (3). 1543-1551.

[27] Thananatthanachon, T.; Rauchfuss, T. B., Efficient Production of The Liquid Fuel 2,5-Dimethylfuran from Fructose using Formic Acid as A Reagent. Angew. Chem. Int. Ed. 2010, 49 (37), 6616-6618.

[28] Zu, Y.; Yang, P.; Wang, J.; Liu, X.; Ren, J.; Lu, G.; Wang, Y., Efficient Production of The Liquid Fuel 2,5-Dimethylfuran from 5-Hydroxymethylfurfural over $\mathrm{Ru} / \mathrm{Co}_{3} \mathrm{O}_{4}$ Catalyst. Appl. Catal. B 2014, 146, 244-248.

[29] Gawade, A. B.; Tiwari, M. S.; Yadav, G. D., Biobased Green Process: Selective Hydrogenation of 5-Hydroxymethylfurfural to 2,5-Dimethyl Furan under Mild Conditions Using Pd-Cs ${ }_{2.5} \mathrm{H}_{0.5} \mathrm{PW}_{12} \mathrm{O}_{40} / \mathrm{K}-10$ Clay. ACS Sustain. Chem. Eng. 2016, 4 (8), 4113-4123.

[30] Kong, X.; Zhu, Y.; Zheng, H.; Li, X.; Zhu, Y.; Li, Y.-W., Ni Nanoparticles Inlaid Nickel Phyllosilicate as a Metal-Acid Bifunctional Catalyst for Low-Temperature Hydrogenolysis Reactions. ACS Catal. 2015, 5 (10), 5914-5920.

[31] Guo, D.; Liu, X.; Cheng, F.; Zhao, W.; Wen, S.; Xiang, Y.; Xu, Q.; Yu, N.; Yin, D., Selective 
Hydrogenolysis of 5-Hydroxymethylfurfural to Produce Biofuel 2, 5-Dimethylfuran over Ni/ZSM-5 Catalysts. Fuel 2020, 274, 117853.

[32] Han, W.; Tang, M.; Li, J.; Li, X.; Wang, J.; Zhou, L.; Yang, Y.; Wang, Y.; Ge, H., Selective Hydrogenolysis of 5-Hydroxymethylfurfural to 2,5-Dimethylfuran Catalyzed by Ordered Mesoporous Alumina Supported Nickel-Molybdenum Sulfide Catalysts. Appl. Catal. B 2020, 268. 118748 .

[33] Saha, B.; Bohn, C. M.; Abu-Omar, M. M., Zinc-Assisted Hydrodeoxygenation of Biomass-Derived 5-Hydroxymethylfurfural to 2,5-Dimethylfuran. ChemSusChem 2014, 7 (11), 3095-3101.

[34] Shen, H.; Shan, H.; Liu, L., Evolution Process and Controlled Synthesis of Humins with 5-Hydroxymethylfurfural (HMF) as Model Molecule. ChemSusChem 2020, 13 (3), 513-519.

[35] Zhang, J.; Ellis, L. D.; Wang, B.; Dzara, M. J.; Sievers, C.; Pylypenko, S.; Nikolla, E.; Medlin, J. W., Control of Interfacial Acid-metal Catalysis with Organic Monolayers. Nat. Catal. 2018, 1 (2), 148-155.

[36] Wu, D.; Hernández, W. Y.; Zhang, S.; Vovk, E. I.; Zhou, X.; Yang, Y.; Khodakov, A. Y.; Ordomsky, V. V., In Situ Generation of Brønsted Acidity in the Pd-I Bifunctional Catalysts for Selective Reductive Etherification of Carbonyl Compounds under Mild Conditions. ACS Catal. 2019, 9 (4), 2940-2948.

[37] Meng, Q.; Hou, M.; Liu, H.; Song, J.; Han, B., Synthesis of Ketones from Biomass-derived Feedstock. Nat. Commun. 2017, 8, 14190.

[38] Ntainjua, N, E.; Piccinini, M.; Pritchard, J. C.; He, Q.; Edwards, J. K.; Carley, A. F.; Moulijn, J. A.; Kiely, C. J.; Hutchings, G. J., The Effect of Bromide Pretreatment on the Performance of Supported Au-Pd Catalysts for the Direct Synthesis of Hydrogen Peroxide. ChemCatChem 2009, 1 (4), 479-484.

[39] Chen, J.; Liu, R.; Guo, Y.; Chen, L.; Gao, H., Selective Hydrogenation of Biomass-Based 5-Hydroxymethylfurfural over Catalyst of Palladium Immobilized on Amine-Functionalized Metal-Organic Frameworks. ACS Catal. 2014, 5 (2), 722-733.

[40] Goyal, R.; Sarkar, B.; Bag, A.; Siddiqui, N.; Dumbre, D.; Lucas, N.; Bhargava, S. K.; Bordoloi, A., Studies of Synergy Between Metal-Support Interfaces and Selective Hydrogenation of HMF to DMF in Water. J. Catal. 2016, 340, 248-260.

[41] Chimentão, R. J.; Oliva, H.; Belmar, J.; Morales, K.; Mäki-Arvela, P.; Wärnå, J.; Murzin, D. Y.; Fierro, J. L. G.; Llorca, J.; Ruiz, D., Selective Hydrodeoxygenation of Biomass Derived 5-Hydroxymethylfurfural over Silica Supported Iridium Catalysts. Appl. Catal. B 2019, 241, 270-283.

[42] Wang, H.; Zhu, C.; Li, D.; Liu, Q.; Tan, J.; Wang, C.; Cai, C.; Ma, L., Recent Advances in Catalytic Conversion of Biomass to 5-Hydroxymethylfurfural and 2, 5-Dimethylfuran. Renew. Sust. Energ. Rev. 2019, 103, 227-247.

[43] Tysoe, W. T.; Lambert, R. M., Surface Chemistry of The Metal-halogen Interface: Bromine Chemisorption and Dibromide Formation on Palladium (111). Surf. Sci. 1982, 115 (1), 37-47.

[44] Ayyoub, S.; Natalie, A. L.; Delphine, F.; Olivier, C.; Farid, C.; Mohamed, T. A Comparative Study of Solvent-Free and Highly Efficient Pinene Hydrogenation over Pd on Carbon, Alumina, and Silica Supports. Org. Process Res. Dev. 2017, 21, 60-64.

[45] Campisi, S.; Ferri, D.; Villa, A.; Wang, W.; Wang, D.; Kröcher, O.; Prati, L., Selectivity 
Control in Palladium-Catalyzed Alcohol Oxidation through Selective Blocking of Active Sites. J. Phys. Chem. C 2016, 120 (26), 14027-14033.

[46] Ball, M. R.; Rivera-Dones, K. R.; Gilcher, E. B.; Ausman, S. F.; Hullfish, C. W.; Lebrón, E. A.; Dumesic, J. A., AgPd and CuPd Catalysts for Selective Hydrogenation of Acetylene. ACS Catal. 2020, 10 (15), 8567-8581.

[47] Nieminen, V.; Honkala, K.; Taskinen, A.; Murzin, D. Y., Intrinsic Metal Size Effect on Adsorption of Organic Molecules on Platinum. J. Phys. Chem. C 2008, 112 (17), 6822-6831.

[48] Bhogeswararao, S.; Srinivas, D., Catalytic Conversion of Furfural to Industrial Chemicals over Supported Pt and Pd Catalysts. J. Catal. 2015, 327, 65-77.

[49] Komanoya, T.; Kinemura, T.; Kita, Y.; Kamata, K.; Hara, M., Electronic Effect of Ruthenium Nanoparticles on Efficient Reductive Amination of Carbonyl Compounds. J. Am. Chem. Soc. 2017, 139 (33), 11493-11499.

[50] An, J.; Wang, Y.; Lu, J.; Zhang, J.; Zhang, Z.; Xu, S.; Liu, X.; Zhang, T.; Gocyla, M.; Heggen, M.; Dunin-Borkowski, R. E.; Fornasiero, P.; Wang, F., Acid-Promoter-Free Ethylene Methoxycarbonylation over Ru-Clusters/Ceria: The Catalysis of Interfacial Lewis Acid-Base Pair. J. Am. Chem. Soc. 2018, 140 (11), 4172-4181.

[51] Pushkarev, V. V.; An, K.; Alayoglu, S.; Beaumont, S. K.; Somorjai, G. A., Hydrogenation of Benzene and Toluene over Size-controlled Pt/SBA-15 Catalysts: Elucidation of The Pt Particle Size Effect on Reaction Kinetics. J. Catal. 2012, 292, 64-72.

[52] Cui, X.; Surkus, A. E.; Junge, K.; Topf, C.; Radnik, J.; Kreyenschulte, C.; Beller, M., Highly Selective Hydrogenation of Arenes Using Nanostructured Ruthenium Catalysts Modified with A Carbon-nitrogen Matrix. Nat. Commun. 2016, 7, 11326.

[53] Jiang, H.; Yu, X.; Nie, R.; Lu, X.; Zhou, D.; Xia, Q., Selective Hydrogenation of Aromatic Carboxylic Acids over Basic N-doped Mesoporous Carbon Supported Palladium Catalysts. Appl. Catal. A 2016, 520, 73-81.

[54] Mitsui, T.; Rose, M. K.; Fomin, E.; Ogletree, D. F.; Salmeron, M., Dissociative Hydrogen Adsorption on Palladium Requires Aggregates of Three or More Vacancies. Nature 2003, 422 (6933), 705-712.

[55] Doudin, N.; Yuk, S. F.; Marcinkowski, M. D.; Nguyen, M.-T.; Liu, J.-C.; Wang, Y.; Novotny, Z.; Kay, B. D.; Li, J.; Glezakou, V.-A.; Parkinson, G.; Rousseau, R.; Dohnálek, Z., Understanding Heterolytic $\mathrm{H}_{2}$ Cleavage and Water-Assisted Hydrogen Spillover on $\mathrm{Fe}_{3} \mathrm{O}_{4}(001)$-Supported Single Palladium Atoms. ACS Catal. 2019, 9 (9), 7876-7887.

[56] Aellig, C.; Jenny, F.; Scholz, D.; Wolf, P.; Giovinazzo, I.; Kollhoff, F.; Hermans, I., Combined 1,4-Butanediol Lactonization and Transfer Hydrogenation/Hydrogenolysis of Furfural-Derivatives under Continuous Flow Conditions. Catal. Sci. Technol. 2014, 4 (8), 2326-2331.

[57] Chidambaram, M.; Bell, A. T., A Two-Step Approach for the Catalytic Conversion of Glucose to 2,5-Dimethylfuran in Ionic Liquids. Green Chem. 2010, 12 (7). 1253-1262.

[58] Volkov, A.; Gustafson, K. P. J.; Tai, C.-W.; Verho, O.; Bäckvall, J.-E.; Adolfsson, H., Mild Deoxygenation of Aromatic Ketones and Aldehydes over Pd/C Using Polymethylhydrosiloxane as the Reducing Agent. Angew. Chem. Int. Ed. 2015, 127 (17), 5211-5215. 

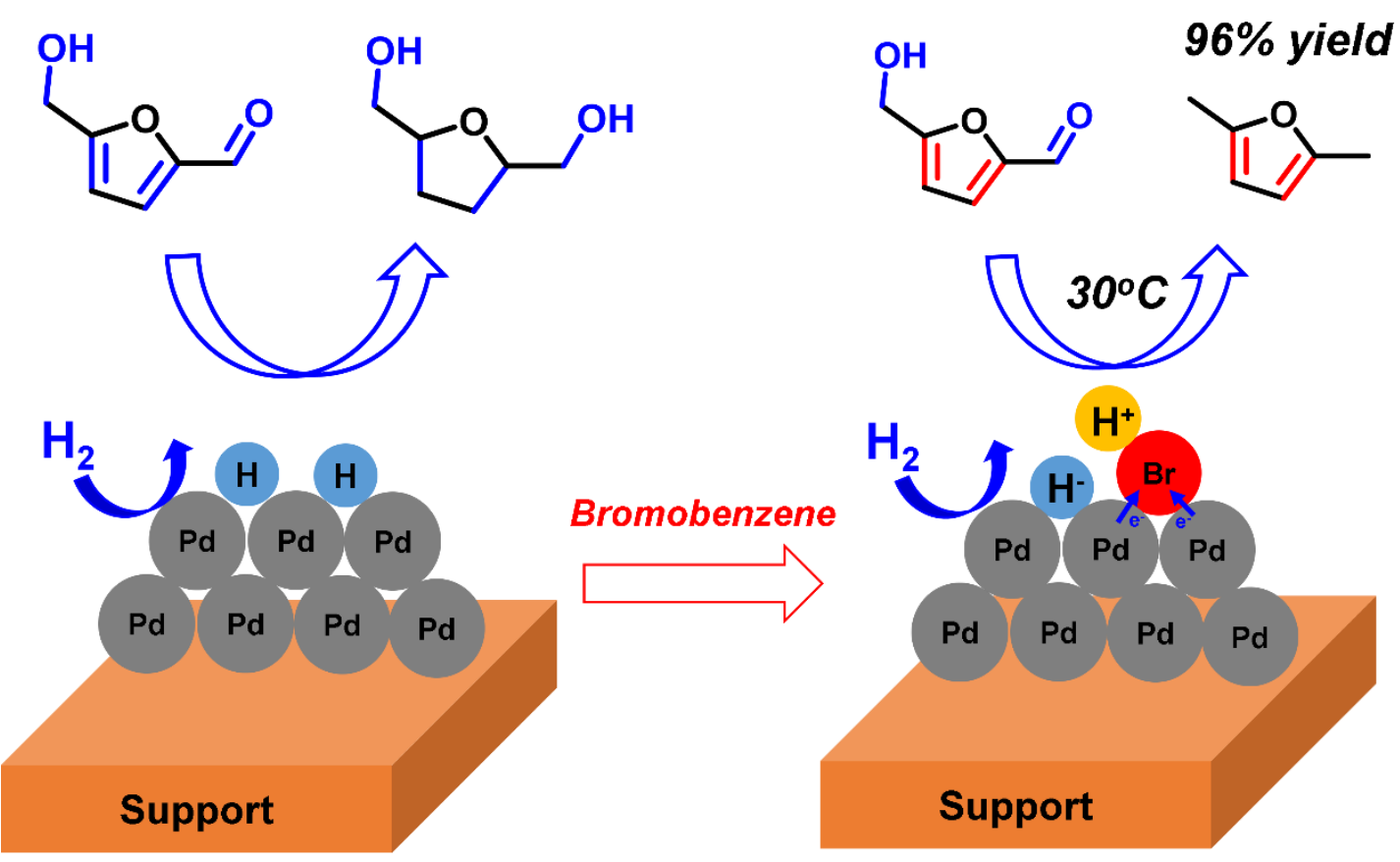